\title{
EFFECTS OF REDUCED SULPHUR ATMOSPHERES ON REFLECTOR MATERIALS FOR CONCENTRATING SOLAR THERMAL APPLICATIONS
}

\author{
A. García-Segura ${ }^{a, 1}$, A. Fernández-García ${ }^{a}$, M.J. Ariza ${ }^{b}$, F. Sutter ${ }^{c}$, L. Valenzuela $^{a}$ \\ ${ }^{a}$ CIEMAT-PSA, Ctra. Senés, km 4, P.O. Box 22, 04200 Tabernas, Almería, Spain \\ ${ }^{\mathrm{b}}$ Universidad de Almería, Física Aplicada, CITE II-A, 04120, Almería, Spain \\ ${ }^{c}$ DLR, German Aerospace Center, Institute of Solar Research, Plataforma Solar de Almería, Ctra. Senés, km 4, P.O. Box 39, 04200 Tabernas, \\ Almería, Spain
}

\begin{abstract}
The degradation of reflector materials for concentrating solar thermal applications is analysed. Corrosion of their metallic reflective layer is considered a major problem in facilities which are located near industrial sites, where reduced sulphur gases may be present. Accelerated ageing tests were performed to study the influence of $\mathrm{H}_{2} \mathrm{~S}$ on the corrosion of two types of silvered glass reflectors and one aluminium reflector. Different degradation patterns were found for silvered glass reflectors, whereas aluminium reflectors did not corrode in the presence of the sulphurous gas. Therefore, industrial pollution caused by this type of gas may decrease the solar collectors' performance.
\end{abstract}

Keywords: silver (A); glass (A); aluminium (A); spectroscopy (B); sulphidation (C); atmospheric corrosion (C)

\author{
Nomenclature \\ Acronyms \\ CSP concentrating solar power \\ PVD physical vapour deposited \\ IEC International Electrotechnical Commission \\ XPS X-ray photoelectron spectroscopy \\ SEM scanning electron microscopy \\ EDS energy dispersive X-ray spectroscopy
}

\footnotetext{
${ }^{1}$ Corresponding author. Tel.: +34 950387 800; Fax: +34 950365 015. E-mail addresses: agarcia@psa.es (A. García-Segura), afernandez@psa.es (A. Fernández-García), mjariza@ual.es (M.J. Ariza), florian.sutter@dlr.de (F. Sutter), loreto.valenzuela@psa.es (L. Valenzuela).
} 


\author{
Symbols \\ $T \quad$ temperature \\ $\mathrm{RH} \quad$ relative humidity \\ $p p \quad$ percentage point \\ $N \quad$ number of corrosion defects
}

\title{
1. Introduction
}

The problematic question related with energy in our present-day society has been and still is of major concern. To tackle it, a significant number of renewable energy technologies have been developed around the world in the last decades [1]. One of the most preeminent and feasible solutions to this worldwide issue is the implementation of plants using concentrating solar thermal technologies (also named concentrating solar power, CSP, plants) [2]. Actually, this kind of technology has experienced a widespread advancement in many countries, led by Spain and USA [3]. Today around 5 GW $_{\text {electric }}$ of CSP capacity is installed worldwide, almost half of it deployed in Spain. The 50 power plants in Spain represent around 3\% of the Spanish electricity generation mix. CSP has reached now an electricity generation cost of $14 \mathrm{c} € / \mathrm{kWh}$ at relatively good sunny places, and with increasing installed capacity a large potential of further cost reduction is foreseen [4].

A CSP facility is integrated by different components including receivers, heat transfer fluids and reflectors. The last ones constitute a large percentage of the total surface of the solar plant and are expected to comply with a high optical performance along their service lifetime (aimed at 10-30 years or more) under demanding environmental conditions [5]. The durability of solar reflectors is one of the crucial factors in the proper operation of any CSP facility. The plants are sometimes located near industries affected by heavily polluted atmospheres, which may give a boost to the corrosion of solar reflectors. Among the most frequent corrosive gases found in the surroundings of industrial sites, hydrogen sulphide $\left(\mathrm{H}_{2} \mathrm{~S}\right)$, sulphur dioxide $\left(\mathrm{SO}_{2}\right)$, nitrogen dioxide $\left(\mathrm{NO}_{2}\right)$, and chlorine $\left(\mathrm{Cl}_{2}\right)$ are considered to be very harmful [6]. In particular, elevated levels of reducing sulphur-based gases $\left(\mathrm{H}_{2} \mathrm{~S}\right.$, sulphur vapour, and mercaptans) are common in a wide range of different industrial environments, such as rubber manufacturing, sewage and waste-water treatment plants, petroleum refineries, coal-generation power plants, pulp and paper mills, and many others from anthropological sources [6-11]. Furthermore, hydrogen sulphide is known to be extremely corrosive to most metals and alloys [12]. For this reason, it is considered to be a target gas to study the durability of solar reflectors facing corrosive atmospheres.

Among the different types of concentrating solar reflectors, back-silvered glass reflectors are the most deployed ones. They are classified as second-surface reflectors because they are based on a thin reflective silver layer which is protected by a 1 to $4 \mathrm{~mm}$ glass substrate on the front side and typically a copper layer and several protective paints on the back side. On the other hand, aluminium reflectors are usually used in small-scale applications, e.g. process heat [13]. They are first-surface reflectors 
composed of a physical vapour deposited (PVD) aluminium layer, which is applied on an aluminium substrate. Transparent $\mathrm{SiO}_{2}$-based sol-gel coatings are used to protect the reflective aluminium layer [14]. Therefore, solar reflectors contain metal sheets and films that are liable to be corroded in a polluted environment.

In the particular case of the silver sulphidation, its corrosion rate is dominantly dependent on the reduced sulphur pollutant concentration. The presence of oxidising species, such as $\mathrm{NO}_{2}, \mathrm{Cl}_{2}, \mathrm{HCl}, \mathrm{O}_{3}, \mathrm{O}_{2}$ $\mathrm{H}_{2} \mathrm{O}$, has been considered to increase it as well [15-17]. The main reaction product of the sulphurous corrosion of silver is silver sulphide $\left(\mathrm{Ag}_{2} \mathrm{~S}\right)$, a monoclinic crystal also known as argentite or acanthite [6, 18]. In those environments slightly polluted with $\mathrm{H}_{2} \mathrm{~S}$, compounds such as sulphates, chlorides [19], and nitrates can be found on the silver surface, whereas $\mathrm{Ag}_{2} \mathrm{~S}$ is the main reaction product in those sites heavily polluted with $\mathrm{H}_{2} \mathrm{~S}$ [20]. If halogens such as bromine or iodine are also present, they can prevent sulphidation from taking place by forming silver bromide or iodide [18]. As a general trend, silver has been found to corrode faster in marine and volcanic environments, where the presence of $\mathrm{H}_{2} \mathrm{~S}$ is higher, than in rural and urban environments [19]. Historically, the major problem with this gas has been the general lack of published data, due to the difficulties in obtaining reliable measurements [9]. In the case of copper, complex copper hydroxides, sulphates, carbonates, and chlorides have been found as the main corrosion products on outdoor exposed samples. The airborne pollutants that have been reported to have a significant influence in copper corrosion are $\mathrm{SO}_{2}, \mathrm{H}_{2} \mathrm{~S}$, and $\mathrm{O}_{3}$, while $\mathrm{NO}_{2}, \mathrm{Cl}_{2}$, and $\mathrm{NH}_{3}$ might have little influence [7, 9]. As for aluminium, Graedel [21] did a thorough review of the corrosion mechanisms involved in the atmospheric exposure of this metal and found that reduced sulphur compounds were not essential in its corrosion chemistry. Only if these species were oxidised in solution to form sulphates, they could play some kind of role in the process, but the great resistance of aluminium to them seems to dismiss this idea. Conversely, aluminium has been proven to be more reactive when exposed to marine environments containing chlorides and to atmospheres with sulphur dioxide [21, 22]. International Electrotechnical Commission (IEC) environmental guidelines for controlled environments classify different types of atmospheres according to their content in chemically active substances including $\mathrm{H}_{2} \mathrm{~S}$ [23]. The typical concentrations of this gas for different atmospheric environments are reported in [6] as $0.6 \mathrm{ppb}$ for clean rooms, $4 \mathrm{ppb}$ for both controlled and rural environments, $200 \mathrm{ppb}$ for urban sites with heavy traffic or industrial facilities, $4075 \mathrm{ppb}$ for places adjacent to industries and $28500 \mathrm{ppb}$ for indoor industrial atmospheres.

Several works have been focused on studying the effects that industrial air atmospheres (including $\mathrm{H}_{2} \mathrm{~S}$ ) may have on various metals, including silver. Many of these works have been devoted to testing electrical contact materials under laboratory accelerated conditions [24, 25]. A great number of experiments combining different corrosive gases were designed and applied to silver and copper, and their correspondent reaction products were analysed. $\mathrm{H}_{2} \mathrm{~S}$ was found to be essential in such simulations, along with combinations of $\mathrm{SO}_{2}$ and $\mathrm{NO}_{2}$ and other atmospheric factors $\left(\mathrm{O}_{2}, \mathrm{H}_{2} \mathrm{O}\right.$, chlorides), which were responsible for the oxidation of $\mathrm{H}_{2} \mathrm{~S}$ and thus providing a reducing source of free sulphur. The most common surface film product in the tests with silver was $\mathrm{Ag}_{2} \mathrm{~S}[7,16,17]$. Other related studies were focused on the influence of relative humidity in the rate of silver and copper sulphidation by $\mathrm{H}_{2} \mathrm{~S}$ and its reaction mechanisms depending on the adsorbed water on the metal surface. Concerning the 
composition of the corrosion films, X-ray photoelectron spectroscopy (XPS) analyses revealed that no oxygen was detected in the case of silver and its sulphur content was much thinner than that of copper, suggesting the formation of metal sulphides and excluding the presence of sulphates or sulphites [26]. According to Kim [15], the presence of oxygen is required for the sulphidation of silver in atmospheres containing $0.1 \mathrm{ppm} \mathrm{H}_{2} \mathrm{~S}$, both at low (15\%) and high (75\%) relative humidity conditions, being the

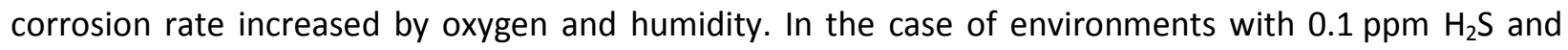
$1.2 \mathrm{ppm} \mathrm{NO}$, elemental sulphur was found to be the oxidising species of the process, being the corrosion rate independent of both oxygen and water contents.

Other works focused their investigations on the atmospheric corrosion (tarnishing) of silver and other metals. The fundamentals of the thin aqueous layer chemistry of the common engineering metals in humid environments were thoroughly studied by Graedel in various manuscripts [21,27]. As stated in [27], the atmospheric corrosion of silver occurs only in the presence of moisture and it rises with increasing relative humidity, although atmospheric corrosion products have been found even at relative humidity values under $70 \%$ [28]. Furthermore, many gases and particles are potentially involved in the indoor atmospheric corrosion of silver, being especially sensitive to the presence of $\mathrm{H}_{2} \mathrm{~S}[27,28,29]$. The only significant source of $\mathrm{H}_{2} \mathrm{~S}$ is in the gas phase and normally its concentration in the aqueous layers on the silver surface, though very low, reaches equilibrium with the atmosphere according to Henry's law and is sufficient to initiate the formation of corrosion films [27]. In the atmosphere, mass transport of pollutants to the silver surface would therefore determine silver sulphidation rate [16].

The presence of reduced sulphur gases implies different possible scenarios. $\mathrm{Ag}_{2} \mathrm{~S}$ or acanthite is found to be the preeminent silver-containing substance when silver is exposed to $\mathrm{H}_{2} \mathrm{~S}$. If this gas concentration is low and the content of oxidisers $\left(\mathrm{O}_{3}, \mathrm{NO}_{2}, \mathrm{Cl}_{2}\right)$ is significant, $\mathrm{Ag}_{2} \mathrm{O}$ and other silver oxides are likely to be the corrosion products. However, when $\mathrm{SO}_{2}$ and $\mathrm{Cl}^{-}$are present, silver sulphates and chlorides may also be formed, taking into account that silver is about an order of magnitude less sensitive to $\mathrm{SO}_{2}$ than to $\mathrm{H}_{2} \mathrm{~S}[9,28]$ and that $\mathrm{SO}_{2}$ appears to have a negligible influence in silver sulphidation in the case of gas mixtures [7, 16]. Both in laboratory and in outdoor environments, nonuniform growth or highly discontinuous nature of $\mathrm{Ag}_{2} \mathrm{~S}$ films is characteristic of silver corrosion $[18,27]$. Recent investigations on silver exposed to sulphur-containing atmospheric environments revealed the presence of $\mathrm{Ag}_{2} \mathrm{SO}_{4}$, which is likely formed from the intermediate $\mathrm{Ag}_{2} \mathrm{SO}_{3}$ and aided by alkali cations, such as $\mathrm{Na}^{+}$. These compounds were not previously reported due to the use of coulometric reduction as the evaluation technique, which does not allow for the detection of highly soluble species, unlike XPS analyses [19, 30].

This paper is focused on studying the consequences for the performance of concentrating solar reflectors when they are exposed to atmospheres containing $\mathrm{H}_{2} \mathrm{~S}$, which has not been previously studied. Using different material analysis techniques, we add information about the corrosion mechanisms of solar reflectors when exposed to this pollutant, we try to identify the corrosion products resulting from the related reactions, and we perform evaluation methods to properly study the degradation mechanisms. Another purpose is to draw some conclusions about the most and least favourable scenarios for reflectors in the presence of $\mathrm{H}_{2} \mathrm{~S}$, depending on the additional environmental conditions, material types, etc. The international standard IEC 60068-2-43:2003 [31] was selected as the reference frame for the experimental design. 


\section{Material and methods}

\subsection{Reflector materials}

Three reflector types were studied, two second-surface silvered glass reflectors (types 1 and 2) and a first-surface aluminium reflector (type 3). To ensure representative results, 3 samples of each reflector type were aged and studied. The samples sizes are appropriate for the measurement instruments and for the testing chamber, namely $(10 \times 10) \mathrm{cm}^{2}$ for silvered reflectors and $(12 \times 12) \mathrm{cm}^{2}$ for aluminium ones. Smaller samples were necessary for the scanning electron microscopy/energy dispersive spectroscopy (SEM/EDS) analyses, and thus $(2 \times 2) \mathrm{cm}^{2}$ samples were also weathered in the ageing tests.

Samples of silvered glass reflector type 1 (Fig. 1a) were cut near the edge of a commercial parabolictrough facet. They feature an original edge, in which the metal layers are completely covered and protected by paint layers (protected edge), and three fractured (or unprotected) edges, in which the cross-section of the metal layers is directly in contact with the polluted atmosphere. In addition, a 2-cmlong scratch (Fig. 1a, right side) was made $2.2 \mathrm{~cm}$ apart from one unprotected edge on the paint side of the samples. 10 strokes were applied with a normalised scratching tool model 426 90064/009 by Erichsen [32] in order to penetrate all the protective paints and metal layers of the reflector up to the glass substrate. This scratch represents an extra initial damage, in which the metal layers are directly exposed to the corrosive atmosphere, and tries to model the real damage that outdoor-exposed samples are prone to encounter due to various reasons, such as aggressive sandstorm conditions [33], undesirable handling, cleaning procedures, etc. Since reflector type 1 samples initially have three fractured edges and the scratch, they exemplify the most adverse case for the silver exposition to the corrosive atmosphere.

Unlike the previous material, samples of silvered glass reflector type 2 (Fig. 1b) have four original edges. They were especially manufactured in $(10 \times 10) \mathrm{cm}^{2}$ format at a lab scale and no scratch was applied to them. Therefore, this reflector type is regarded as initially not damaged. Aluminium reflector samples (Fig. 1c) were sheared from bigger aluminium sheets and include both unprotected edges and a $2-\mathrm{cm}$ scratch at their front side, in the same way as previously mentioned for type 1 samples.

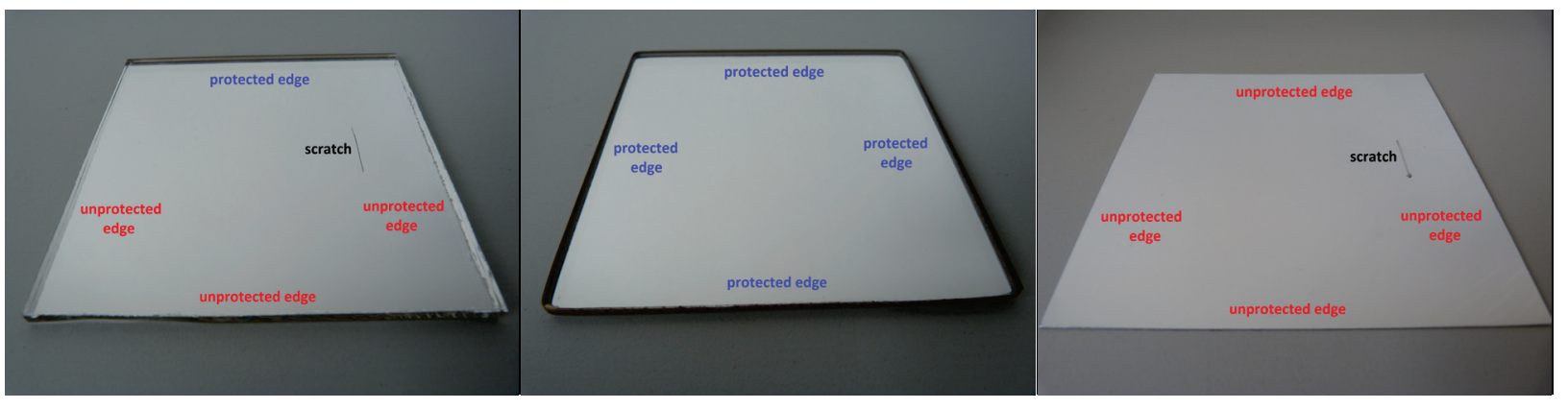

Fig. 1. Overview of the samples tested: silvered glass reflector type 1 with one protected edge, three unprotected edges and one scratch (a), silvered glass reflector type 2 with four protected edges (b) and 
aluminium reflector with four unprotected edges and one scratch (c). The protected edges are labelled in blue, the unprotected edges in red and the scratch in black.

\subsection{Corrosion experiments}

Tests were based on the international standard IEC 60068-2-43:2003, Environmental testing - Part 2-43: Tests - Test Kd: Hydrogen sulphide test for contacts and connections [31]. This standard is devoted to study the influence of atmospheres with $\mathrm{H}_{2} \mathrm{~S}$ in the properties of contacts and connections made of silver, silver alloys, and coating-protected silver. However, it was applied to investigate the corrosion of silvered glass and aluminium solar reflectors, owing to the lack of specific standards for these materials.

The VCC 0034 Vötsch weathering chamber with $125 \mathrm{dm}^{3}$ inner capacity (Figs. 2a and 2b) was used for the corrosion experiments at an elevated dose of $\mathrm{H}_{2} \mathrm{~S}$. An air flow carried the gas dose from an $\mathrm{H}_{2} \mathrm{~S}$ bottle through a particle filter and an adsorbance column with a desiccant cartridge before entering the testing chamber. This chamber can work at temperatures $(T)$ from $+15^{\circ} \mathrm{C}$ to $+60^{\circ} \mathrm{C}$ and relative humidities $(R H)$ from $10 \%$ to $85 \%$.

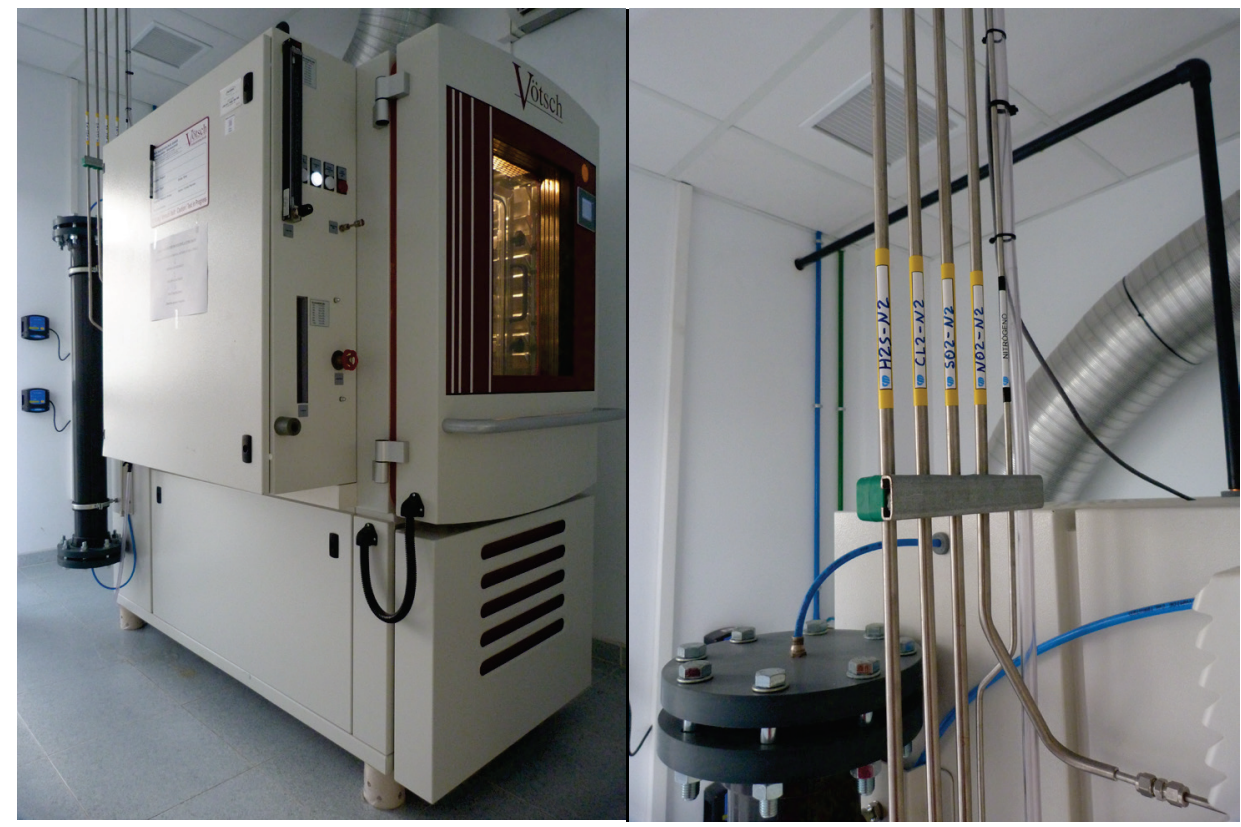

Fig. 2. Weathering chamber $\mathrm{VCC}^{3} 0034$ by Vötsch (a) and detail of the pipelines of gases (b).

Table 1 summarises the experimental conditions of the corrosion tests, which have been selected in accordance to the aforementioned standard. The $\mathrm{H}_{2} \mathrm{~S}$ concentration was fixed at $15 \mathrm{ppm}$, close to four times the value of the typical $\mathrm{H}_{2} \mathrm{~S}$ concentration for places adjacent to industries, while the temperature and relative humidity were set at $T=25^{\circ} \mathrm{C}, R H=75 \%$ for standard conditions (named as SC2 test) and at $T=60^{\circ} \mathrm{C}, R H=85 \%$ for extreme conditions (EC2 test). For comparison, both experiments were also performed without the corrosive gas (SC1 and EC1 tests). To remember these experimental conditions, the $\mathrm{H}_{2} \mathrm{~S}$ concentration, temperature and relative humidity will be added at the end of the test name in the results and discussion section, e.g. SC1(0-25-75) or EC2(15-60-85). 
Table 1. Experimental details of the corrosion tests; standard conditions without gas (SC1), standard conditions with gas (SC2), extreme conditions without gas (EC1), extreme conditions with gas (EC2).

\begin{tabular}{|c|c|c|c|}
\hline Name of test & {$\left[\boldsymbol{H}_{\mathbf{2}} \mathbf{S}\right](\mathbf{p p m})$} & $\boldsymbol{T}\left({ }^{\circ} \mathbf{C}\right)$ & $\boldsymbol{R H}(\%)$ \\
\hline SC1 & 0 & 25 & 75 \\
\hline SC2 & 15 & 25 & 75 \\
\hline EC1 & 0 & 60 & 85 \\
\hline EC2 & 15 & 60 & 85 \\
\hline
\end{tabular}

Samples were set on a tray made of an inert material that held them at $45^{\circ}$ tilt angle inside the chamber. They were taken out of the corrosion chamber after 4, 7, 10, 14, and 21 days, rinsed with deionised water and characterised to determine their performance and the existence of corrosion features.

\subsection{Reflector performance and corrosion characterisation}

The following instruments were used to quantify the performance of the solar reflectors:

- A portable specular reflectometer model 15R-USB, manufactured by Devices and Services [34]. It measures monochromatic specular reflectance with and incidence angle of $15^{\circ}$ and in a wavelength range between 635 and $685 \mathrm{~nm}$, with a peak at $660 \mathrm{~nm}$. The measurements were taken at $12.5 \mathrm{mrad}$ of acceptance angle on nine different areas of the reflector, as indicated in Fig. 3. As can be observed in this figure, the middle right-hand zone (A8) happens to coincide with the area of the scratch for those samples with scratch. Consequently, the specular reflectance value of this spot is treated separately from the rest eight points of the sample. Besides, three repetitions of the specular reflectance measurement at the scratch were made to have statistically representative results. In those samples without scratch, the average specular reflectance value considers the nine points described. Error bars in the graphs represent the standard deviation of the values obtained for the three samples used per material type.

- A spectrophotometer model Lambda 1050, manufactured by Perkin Elmer [35]. It measures spectral hemispherical reflectance with a $150-\mathrm{mm}$ diameter integrating-sphere accessory. The wavelength range measured was from 280 to $2500 \mathrm{~nm}$, using $5 \mathrm{~nm}$ intervals and an incidence angle of $8^{\circ}$. Solar-weighted hemispherical reflectance was calculated according to ISO Standard 9050 [36] and the solar direct radiation spectrum from ASTM G173-03 [37]. Measurements with the spectrophotometer were taken at the centre of the reflector and repeated at the same point thrice (at $0^{\circ}, 90^{\circ}$ and $180^{\circ}$ ) to check any possible anisotropy. Error bars in the graphs represent the standard deviation of the values obtained for the three samples used per reflector type.

- A 3D light microscope model Axio CSM 700, manufactured by Zeiss. Pictures of the reflective layer and the paint side of reflectors were taken at $5 x$ and 10x magnifications and defects features were characterised in size and depth. The characteristic length of a corrosion 
defect is considered its maximum dimension. For instance, if the defect had an irregular round shape, its characteristic length would be its longest diameter. 2D surface profiles were performed at 60 seconds scan time, $0.42 \mu \mathrm{m}$ resolution and 180 frame count.

- A SEM model S-3400N, coupled with an EDS unit model Bruker-ADX, manufactured by Hitachi. Pictures were recorded on Au/Pd-metallised samples (approximately $10 \mathrm{~nm}$ of covering material) with an acceleration voltage of $15 \mathrm{kV}$ at a working distance of around $10 \mathrm{~mm}$. Punctual EDS analyses were performed with a magnification of $200 \mathrm{x}$ on the targeted points of interest.

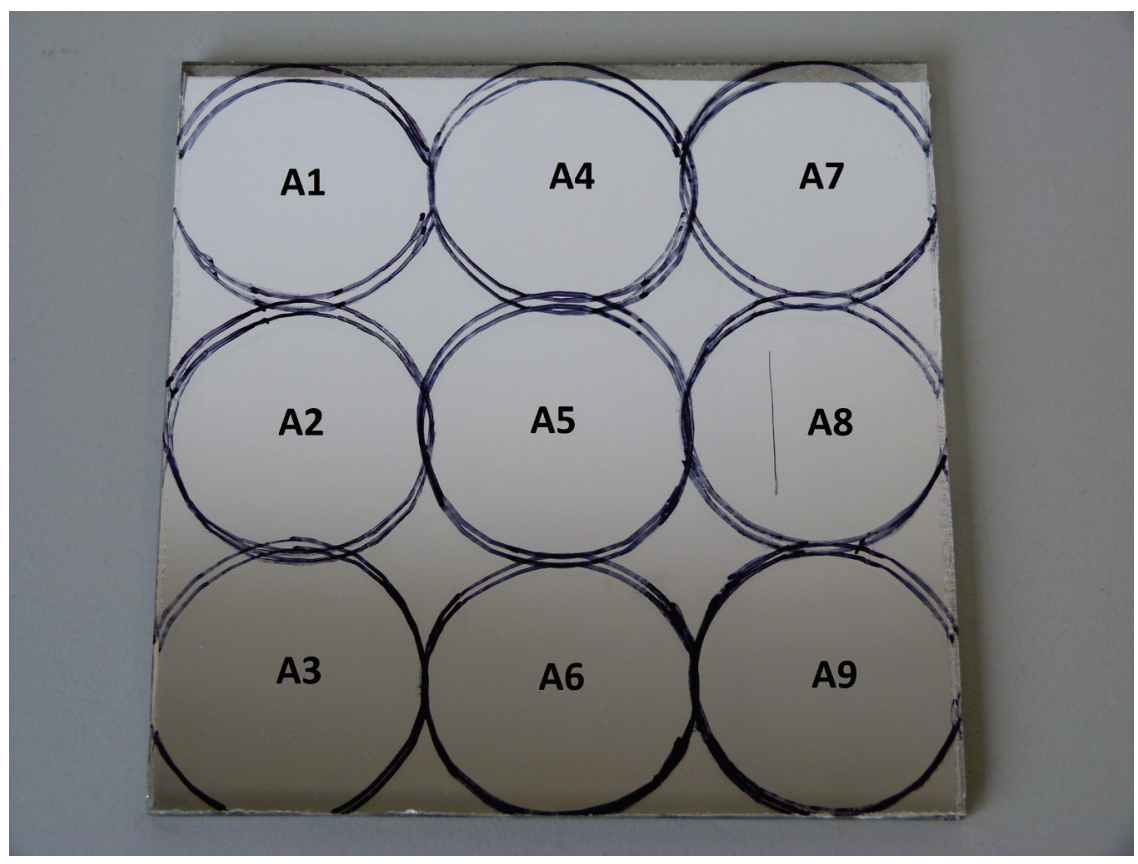

Fig. 3. Selected areas for monochromatic specular reflectance measurements on the reflector samples. The scratch (if present) is located in the A8 zone, while the rest of areas correspond to originally undamaged reflective surface.

\section{Results and discussion}

This section includes the results obtained for the three material types studied, the second-surface silvered glass reflectors types 1 and 2, and the first-surface aluminium reflector. The evolution of the significant reflectance parameters and the changes of corroded areas of the whole sample surface, as well as the 2D profiles and SEM/EDS results at the scratch, are presented and discussed for each material in the different tests performed.

\subsection{Silvered glass reflectors type 1}

As mentioned above, reflectance is the key parameter when studying the efficiency of a solar reflector. The reflector performance can be determined by the monochromatic specular reflectance, which was measured at nine different positions on the sample, and the solar-weighted hemispherical reflectance 
measured in the central area. Figs. $4 a$ and $4 \mathrm{~b}$ depict the results of the specular and hemispherical reflectance, respectively, versus the corrosion testing time for every type of corrosion test (SC1, SC2, $E C 1$, and EC2). As may be observed in these two graphs, no significant decrease in monochromatic specular reflectance is found for these samples in either of the tests, except for a loss of barely $-0.002 \mathrm{pp}$ in the EC2 test. Nevertheless, this value can be considered negligible because it is within the measurement uncertainty of the equipment. Very similar results are obtained for the decrease in solarweighted hemispherical reflectance.

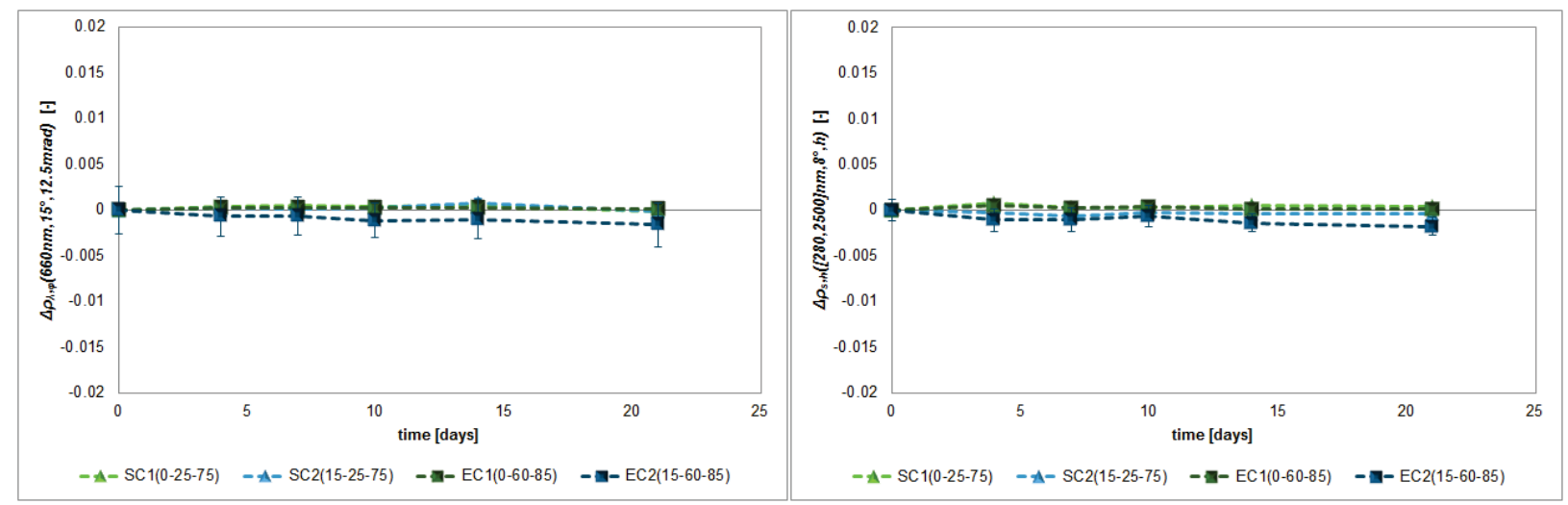

Fig. 4. Evolution along days of the mean change in monochromatic specular reflectance on the eight areas of measurement not initially damaged (a) and in solar-weighted hemispherical reflectance (b) for silvered glass reflectors type 1 in the different tests (light-green triangles for SC1, light-blue triangles for SC2, dark-green squares for EC1 and dark-blue squares for EC2).

Despite the negligible loss in reflectance parameters, the samples feature corrosion spots, especially after the EC2 test. Subsequent microscopic inspections reveal corrosion patterns as those shown in Fig. $5 \mathrm{a} 2$ near the original edge (protected edge), in Fig. $5 \mathrm{~b} 2$ near a fractured edge (unprotected edge) and in Figs. $5 \mathrm{c} 2$ and $5 \mathrm{~d} 2$ far from the edge. This type of degradation consists of black microspots smaller than $200 \mu \mathrm{m}$, not visible to the naked eye, which either grow from the edge up to a maximum advance of almost $600 \mu \mathrm{m}$ (Figs. 5a2, 5b2) or gather together forming macrospots (Figs. 5c2, 5d2). These macrospots are visible to the naked eye and have a maximum characteristic length of $700 \mu \mathrm{m}$.
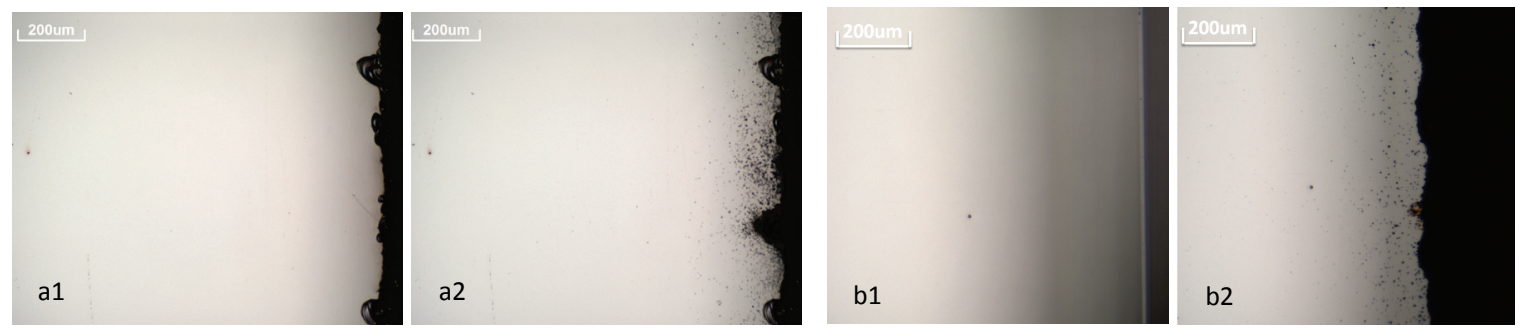

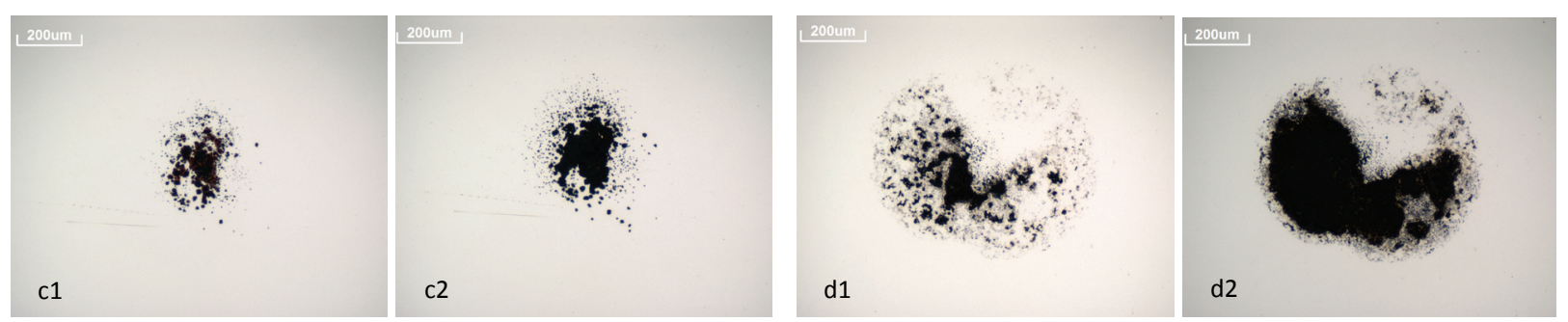

Fig. 5. Microscopic pictures of the evolution of edges before and after EC2 test, and the growth along the test of some macrospots found in the reflective layer of silvered glass reflectors type 1; protected edge before test (a1); protected edge after test (a2); unprotected edge before test (b1); unprotected edge after test (b2); macrospot after 7 days of test (c1); macrospot after 21 days of test (c2); macrospot after 10 days of test (d1); macrospot after 21 days of test (d2).

The loss in monochromatic specular reflectance on the reflector area that was intentionally damaged from the beginning of the tests (i.e. the scratch) is also evaluated (Fig. 6). The most notable change occurs in the EC2 test, followed by the SC2 test. Samples in the EC2 test attain a maximum specular reflectance loss of $-0.076 \mathrm{pp}$ after 21 days, whereas samples in the SC2 test suffer from a decrease in specular reflectance of $-0.011 \mathrm{pp}$ at the end of the test. SC1 and EC1 tests do not provoke any specular reflectance change in these reflector samples, which indicates that the reflectance decay is linked to the presence of $\mathrm{H}_{2} \mathrm{~S}$ in the testing chamber. If EC2 and SC2 tests are compared, a substantial increase in the degradation of the scratch is detected in EC2 due to the higher $T$ and $R H$ conditions, as was already pointed out in previous works $[15,27]$. In addition, as the reflectance loss is only noticed in the area of the scratch, it can be concluded that the reflectance of this type of reflector material remains almost unaffected by the corrosive gas. This conclusion has the nuance that the reflectance in the whole reflector area may have actually decreased after the formation of the corrosion spots, but it is very unlikely to be detected because it is not feasible to cover the whole sample surface when using the traditional reflectance measurement methods.

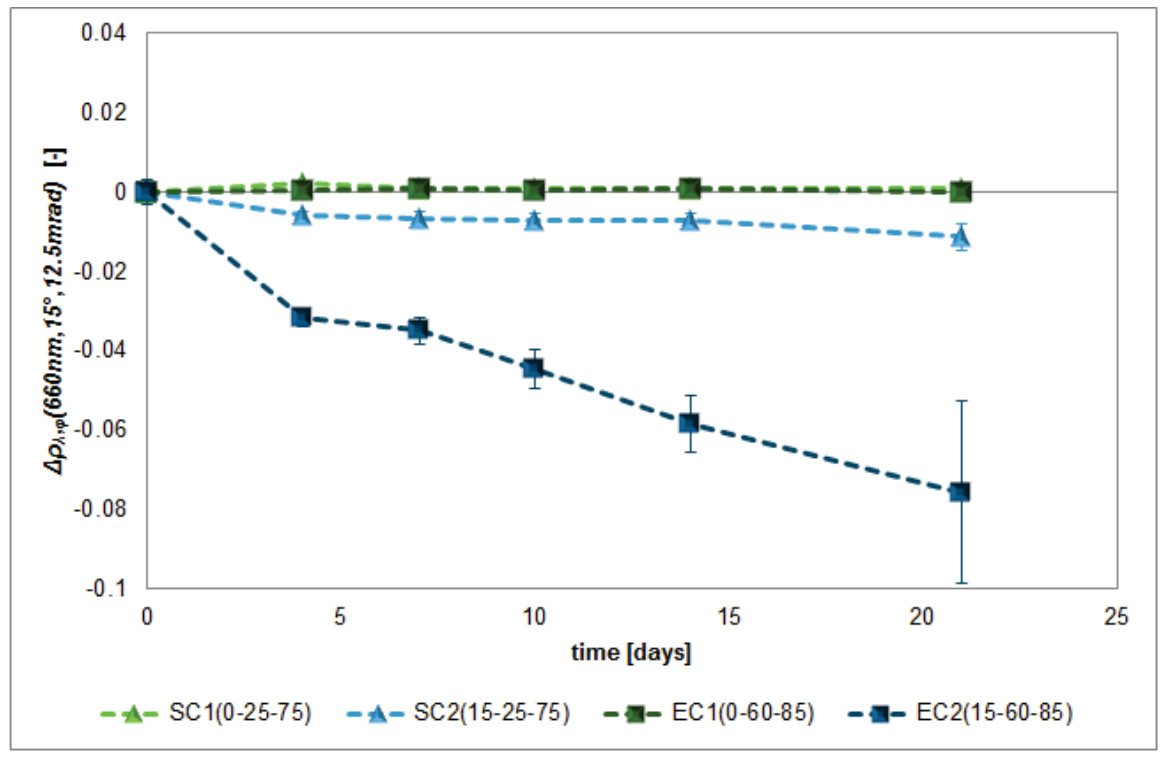


Fig. 6. Evolution along days of the change in monochromatic specular reflectance at the scratch for silvered glass reflectors type 1 in the different tests (light-green triangles for SC1, light-blue triangles for SC2, dark-green squares for EC1 and dark-blue squares for EC2).

Microscopic inspections were made at the scratch and a certain development of corrosion is detected after the tests (Fig. 7). Consistently with the results presented above, the most developed scratch is for the EC2 test (Fig. 7d), followed by the SC2, EC1 and SC1 tests (Figs. 7c, 7b, 7a). Hence, the evolution of the corrosion growth near the scratch along days is estimated by the increment of the maximum scratch width, taking into account that the initial scratch width must be subtracted in the subsequent width measurements (Fig. 8). These results demonstrate that the sulphurous gas enhances corrosion, since the average increment width of the corroded scratch is higher for the tests with gas (SC2, EC2) than for those without it (SC1, EC1). In fact, after the EC2 test the maximum scratch width increases by nearly 7 times its initial value (see Fig. 7d). Similar trends can be observed in the evolution of the scratch width for the tests with gas. Firstly, the corrosion growth is very steep during the initial 4 days of test. Then, it becomes rather stable in the following 10 days, approximately. Finally, it increases again and attains its maximum value after 21 days. A different behaviour is found in the samples aged without the corrosive gas, since the increase of the scratch width is insignificant if compared to the previous samples. This increment starts to be noticeable after more than 7 days of the EC1 test and after more than 14 days of the SC1 test. If Figs. 6 and 8 are compared, a similar behaviour is found between the change in monochromatic specular reflectance and the corrosion growth near the scratch. In both cases, the EC2 test (the one with gas and the extreme conditions) is the most aggressive one, followed by the SC2 test, while the two tests without gas (EC1 and SC1) provoke an almost negligible effect.

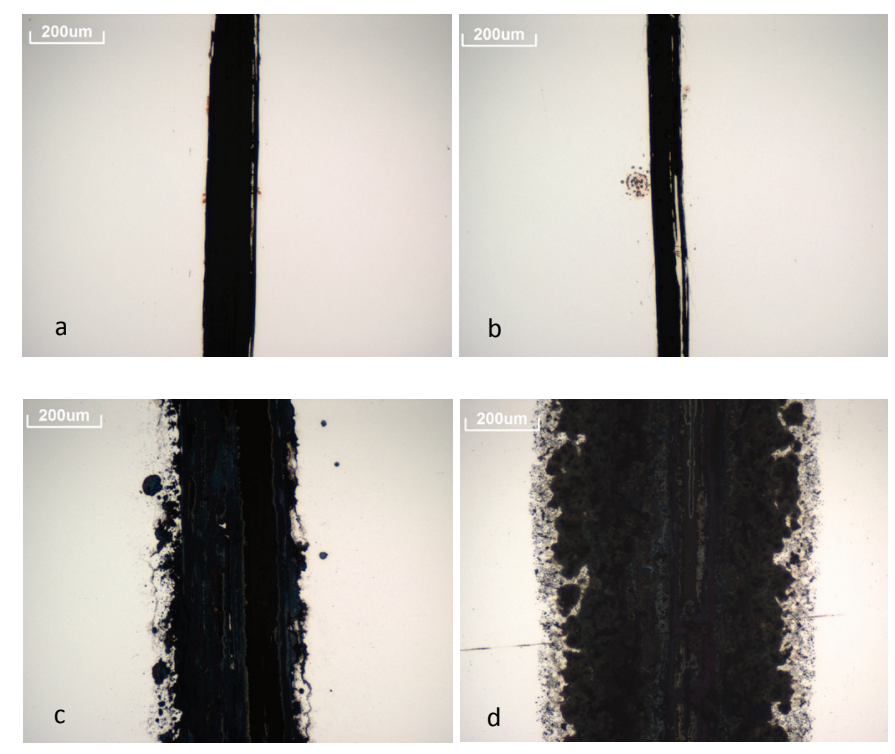

Fig. 7. Microscopic scratch appearance on the reflective side of silvered glass reflectors type 1 after 21 days of SC1 (a), EC1 (b), SC2 (c), and EC2 (d) tests. 


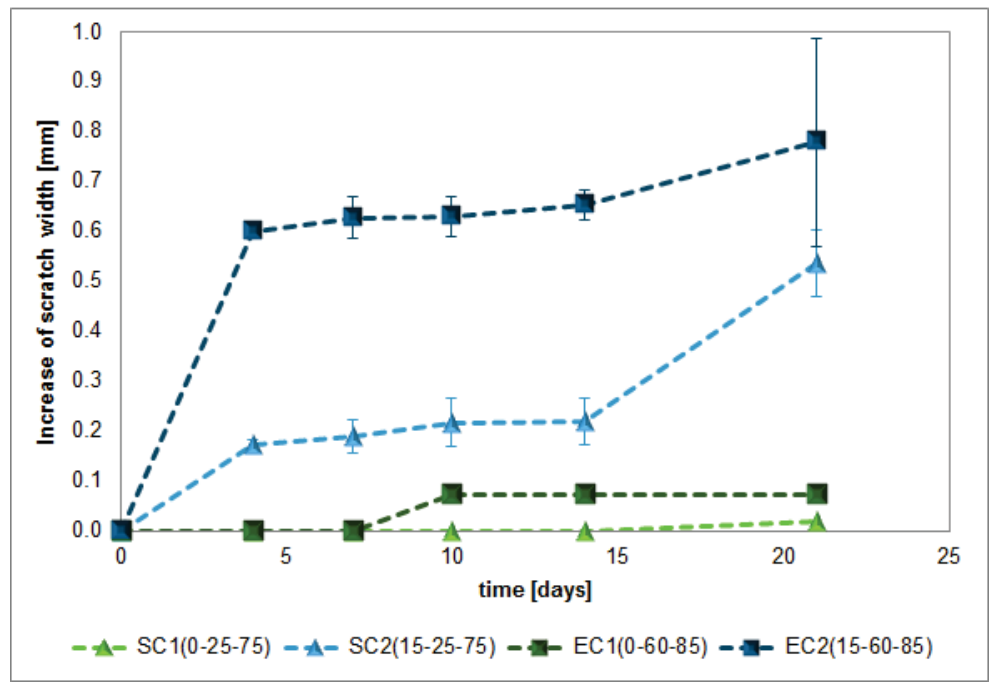

Fig. 8. Increase of the maximum scratch width (in $\mathrm{mm}$ ) as a function of the ageing time for silvered glass reflectors type 1 in the different corrosion tests (light-green triangles for SC1, light-blue triangles for SC2, dark-green squares for EC1 and dark-blue squares for EC2).

The changes in the 2D profiles of the scratch after 21 days of the different tests were also measured on the paint side of samples. The initial scratch depth in the different samples is normally variable and ranges from 90 to 130 microns, approximately. An example of the initial scratch profile and its microscopic appearance before the tests is illustrated in Fig. 9. Initially, the scratch profile is very smooth without any significant irregularities (Fig. 9a). Furthermore, the four layers of the reflector (glass, metals, inner paints, outer paint) can be easily discernible at the scratch before the corrosion tests, since they have different optical properties (Fig. 9b).
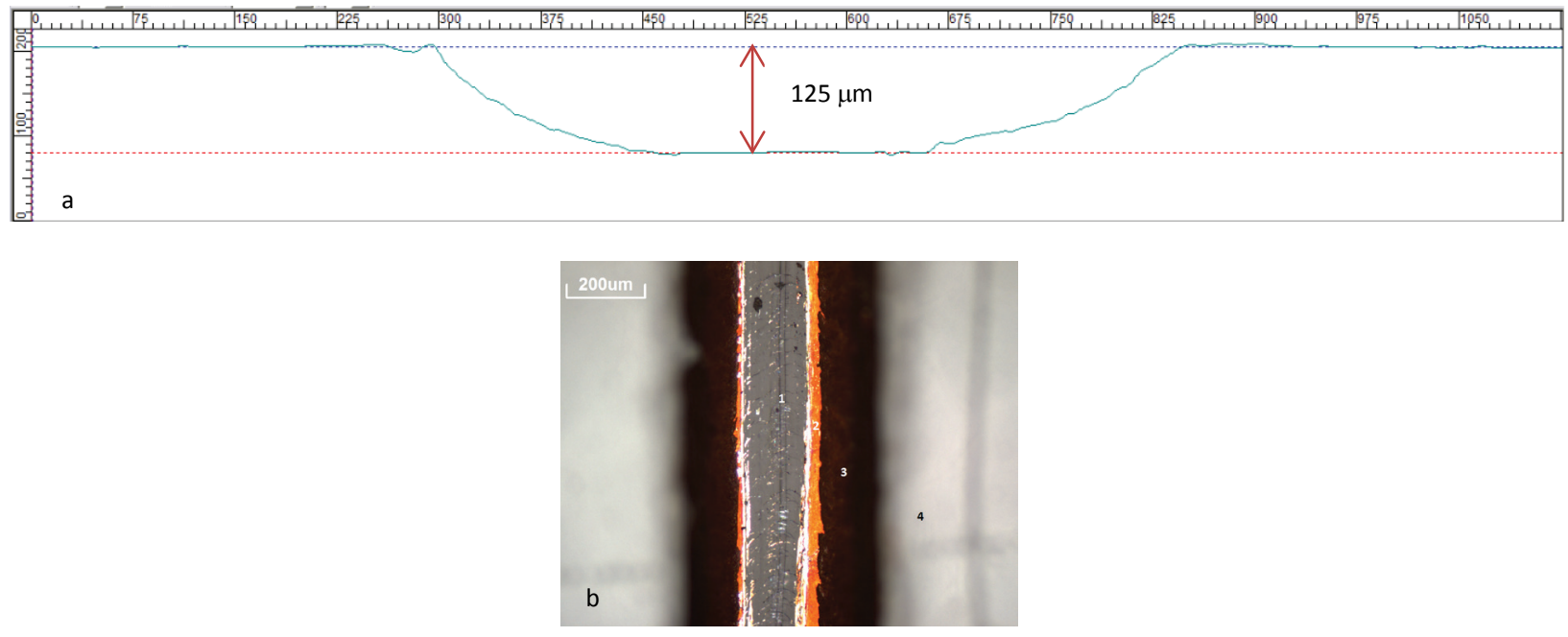

Fig. 9. Typical initial scratch for silvered glass reflectors type 1. a) Scratch profile with a depth of $\sim 125 \mu \mathrm{m}$ (contained between the dotted blue and red lines); b) microscopic picture of the scratch focused on its lowest part, i.e. on the glass substrate. Point 1 corresponds to the glass substrate (in 
grey), point 2 to the metallic layer (silver in white, copper in orange), point 3 to the cut underlying paints (in dark brown and black) and point 4 to the outer paint (in light grey).

After 21 days of SC1 and EC1 tests (without gas) the scratch does not suffer from significant changes in its 2D profile, as can be seen in Figs. 10a and 10b, respectively, if compared to Fig. 9a. With respect to the appearance of the scratch, in the SC1 test no significant change is obtained after the test (Fig. 10a1) comparing with its initial appearance (Fig. 9b). In the case of the EC1 test, some changes between the scratch appearance before and after the test may be observed, such as a dimmer gloss of the reflective layer and a few deposits on the glass substrate (Fig. 10b1). However, as can be seen in Figs. 10c and 10d, experiments SC2 and EC2 (with gas) provoke some noteworthy changes in the scratch profile, which correspond to corrosion deposits that appear as crests in the 2D scans (red circles). Also the scratch width is significantly reduced due to the same reason, mainly after the EC2 test (see Fig. 10d). The increase in roughness and the reduction in the scratch width are more noticeable in the particular case of the EC2 test (extreme conditions with gas). Some of the corrosion deposits reach $30 \mu \mathrm{m}$ high. Regarding the aspect of the scratch, some important changes between its characteristics before and after the SC2 test can be observed, including a significant loss in the reflective layer gloss and detectable deposits on the glass substrate (Fig. 10c1). Finally, remarkable changes in the scratch appearance after the EC2 test can be easily recognised, including an almost total loss of gloss in the reflective layer and numerous corrosion deposits on the glass substrate that completely modify the normal features of the scratch (Fig. 10d1). These results are in accordance with the aforementioned reflectance loss and corrosion growth results at the scratch for this reflector type.
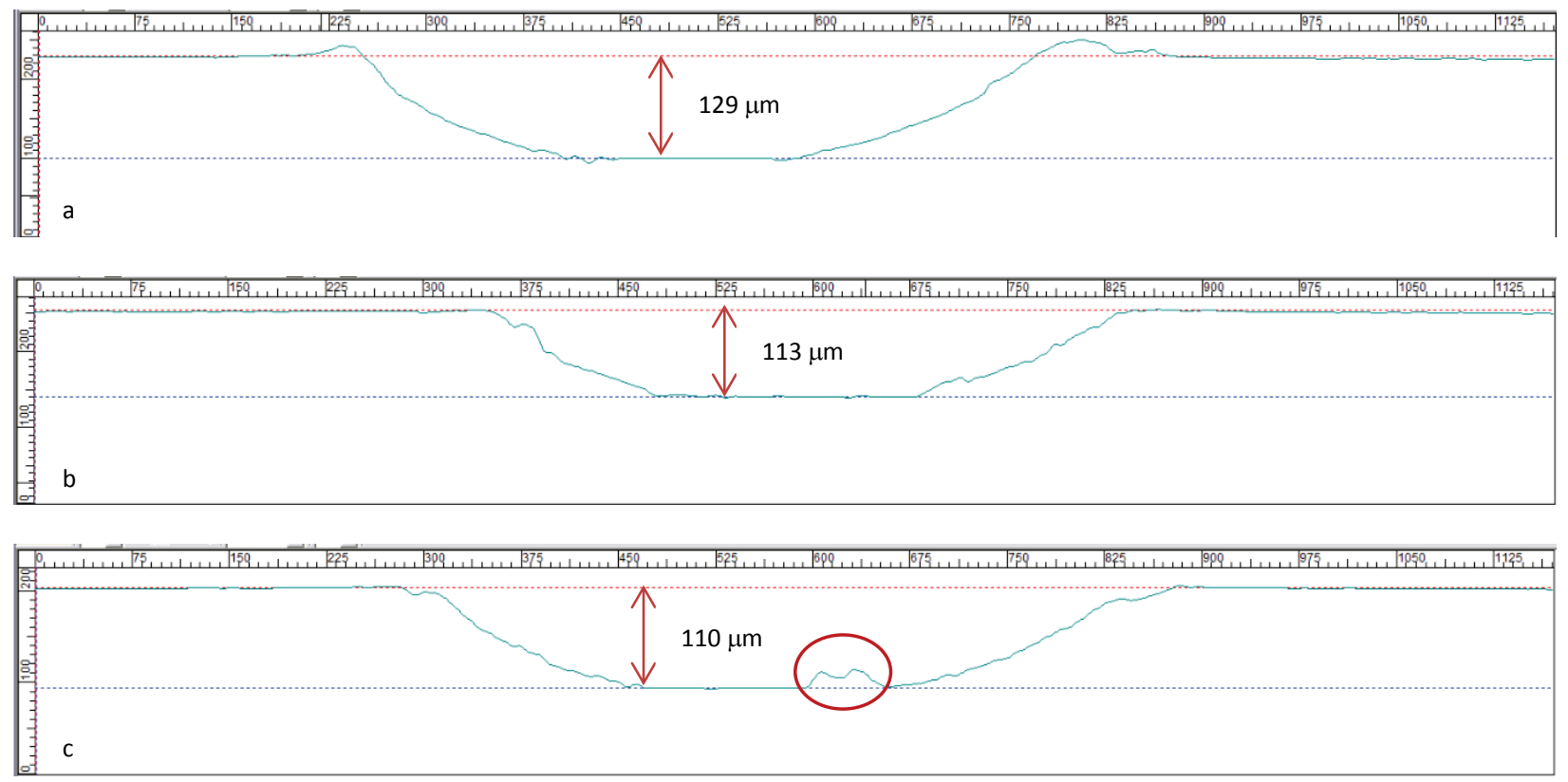

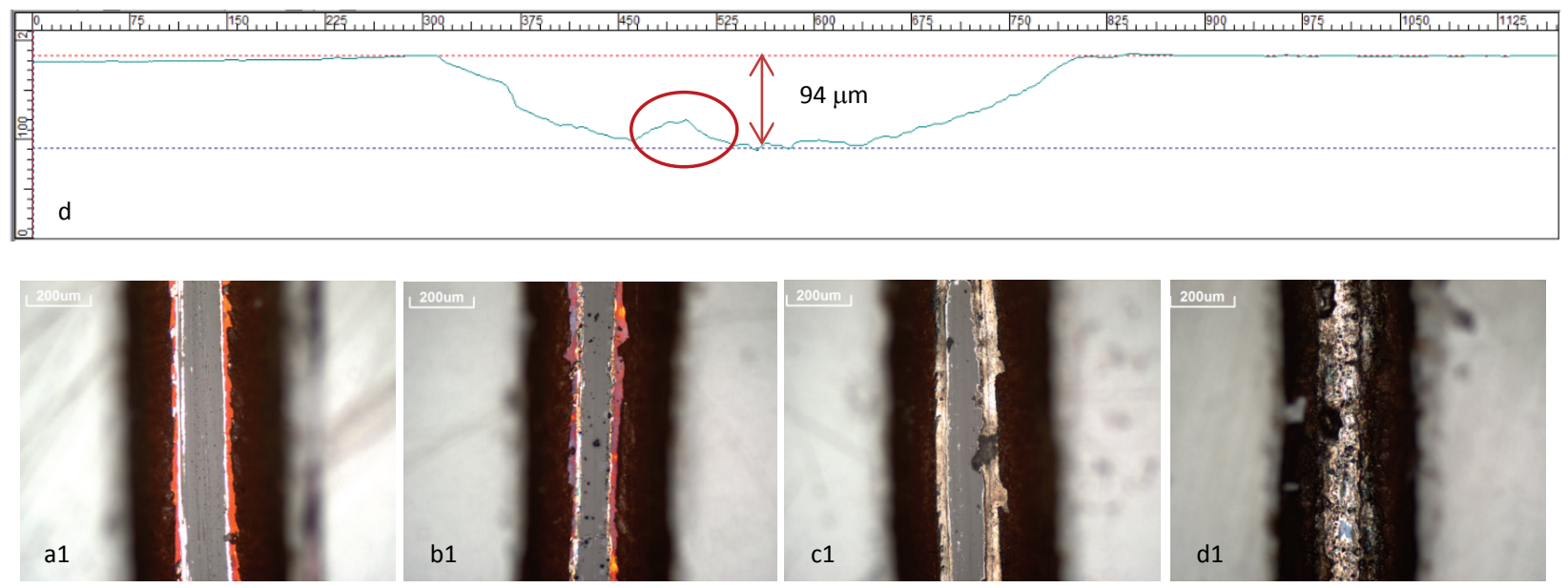

Fig. 10. Scratch profiles for silvered glass reflectors type 1 after 21 days of SC1 (a), EC1 (b), SC2 (c), and EC2 (d) tests. Below, microscopic pictures of the analysis area focused on the glass substrate after SC1 (a1), EC1 (b1), SC2 (c1), and EC2 (d1) tests.

The corrosion near the scratch of both original and aged reflectors was also studied by SEM and EDS microanalyses. Fig. 11 shows SEM images at the scratch of a silvered glass reflector type 1 before (a) and after (b) the EC2 corrosion test. Four regions of different materials can be identified from the different grey colour levels. In correspondence with the optical image of Fig. 9b, the four regions correspond to the glass substrate (point 1 ), the metallic layer (point 2), the underlying paints (point 3 ) and the outer paint (point 4).
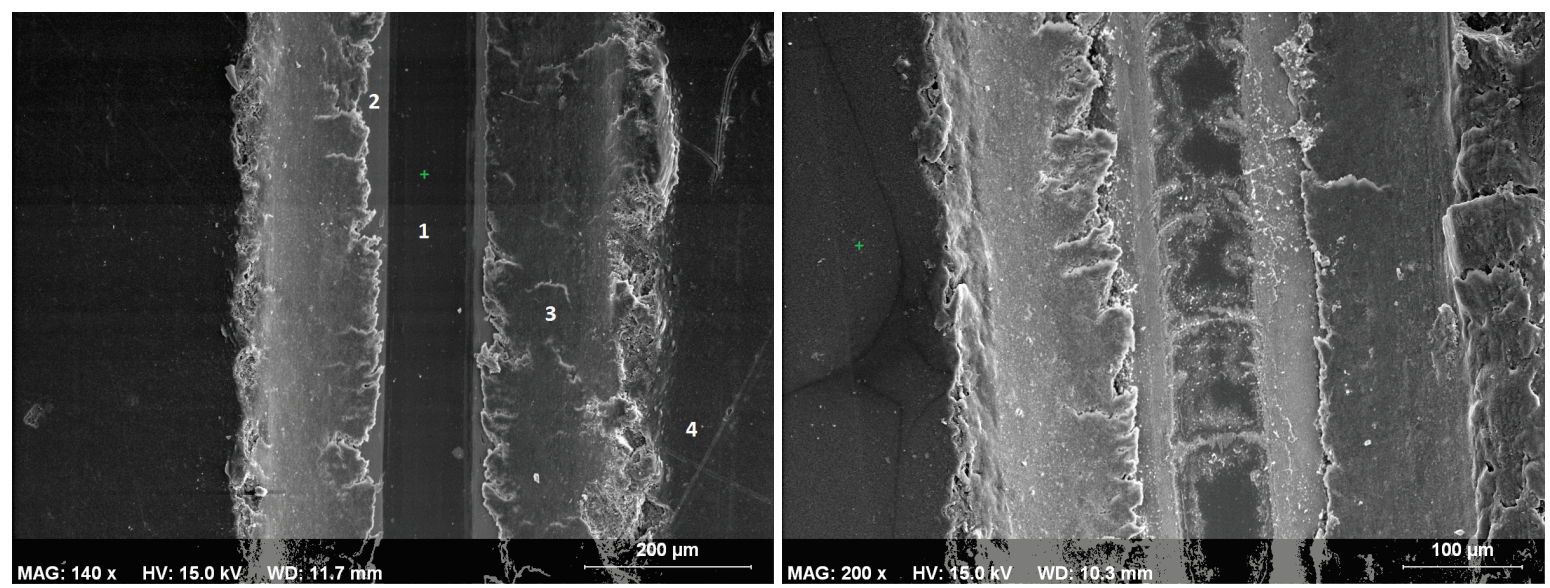

Fig. 11. SEM images of the scratch areas analysed by EDS for silvered glass reflectors type 1 before (a) and after (b) the EC2 test; the four analysis points are the glass substrate (1), the metallic layer (2), the inner paint layers (3), and the outer paint layer (4).

EDS microanalyses were performed at these four points for every sample before and after 21 days of the different corrosion tests, and results are listed in Table 2. In the original sample (before test) at point 1 (glass substrate) $\mathrm{O}$ and $\mathrm{Si}$ are the most abundant elements, whereas $\mathrm{Al}$ and different alkali and alkaline earth metals are detected at lower concentrations, as usual for silicate glasses. At point 2 (metallic layer) 
the expected metallic elements $\mathrm{Cu}$ and $\mathrm{Ag}$ are detected, being $\mathrm{Cu}$ the most abundant one. This suggests that the copper layer is on the top and/or is thicker than the silver layer. Apart from these characteristic metals, the elements already found in the glass substrate $(\mathrm{Si}, \mathrm{Al}, \mathrm{Na}, \mathrm{Ca}, \mathrm{Mg})$ and some others from the paint layers ( $\mathrm{C}$ and $\mathrm{Ti}$ ) are also detected and quantified at point 2 . The composition in the inner and outer paints (points 3 and 4 , respectively) is also typical of paints, since $C$ and $O$ are the most abundant chemical elements in terms of relative atomic percentages. Heavy metals such as $\mathrm{Zn}, \mathrm{Fe}, \mathrm{Pb}$, and $\mathrm{Ba}$ are characteristic elements of the inner paint layers, while $\mathrm{Ti}$ is the most abundant metal in the outer paint layer.

After SC1 and EC1 tests, the same elements already mentioned for the original sample are detected in every point. However, if the relative atomic concentrations of these aged samples are compared to the ones of the original sample, an increment of metal oxidation and ionic diffusion between adjacent materials of the reflective layer occur, due to the higher temperature and relative humidity conditions. In fact, the oxygen percentages increase from $21.78 \%$ for the original sample to $39.67 \%$ for the EC1-aged sample at point 2 , while the $\mathrm{Ag}$ and $\mathrm{Cu}$ percentages decrease. It is also remarkable that a small amount of sulphur atoms are detected in the paint layers only for the extreme conditions without gas (EC1 test).

Table 2. Relative atomic concentrations (\%) of the elements found by EDS microanalyses at the four points on the scratch before and after the different corrosion tests.

\begin{tabular}{|c|c|c|c|c|c|c|c|c|c|c|c|c|c|c|c|c|}
\hline \multirow{2}{*}{ Test } & \multirow{2}{*}{ Point } & \multicolumn{15}{|c|}{ Relative atomic concentrations (\%) } \\
\hline & & 0 & Si & $\mathrm{Na}$ & $\mathrm{Ca}$ & Al & Mg & $\mathrm{Cu}$ & $\mathrm{Ag}$ & C & $\mathrm{Ti}$ & $\mathrm{Zn}$ & $\mathrm{Fe}$ & $\mathrm{Pb}$ & $\mathrm{Ba}$ & $\mathbf{S}$ \\
\hline \multirow{4}{*}{ 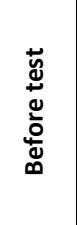 } & 1 & 72.39 & 24.53 & 1.82 & 0.71 & 0.32 & 0.22 & - & - & - & - & - & - & - & - & - \\
\hline & 2 & 21.78 & 11.39 & 1.14 & 0.46 & 0.22 & 0.27 & 34.73 & 6.44 & 23.29 & 0.27 & - & - & - & - & - \\
\hline & 3 & 57.36 & 0.95 & 0.14 & 0.44 & 0.14 & 0.13 & - & - & 38.33 & 0.16 & 0.94 & 0.92 & 0.37 & 0.13 & - \\
\hline & 4 & 41.68 & 0.28 & - & - & 0.04 & 0.10 & - & - & 56.97 & 0.93 & - & - & - & - & - \\
\hline \multirow{4}{*}{ 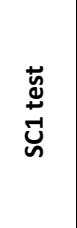 } & 1 & 75.07 & 22.40 & 1.34 & 0.67 & 0.31 & 0.21 & - & - & - & - & - & - & - & - & - \\
\hline & 2 & 26.88 & 9.68 & 1.16 & 0.37 & 0.21 & 0.22 & 27.64 & 5.95 & 27.23 & - & - & - & - & 0.66 & - \\
\hline & 3 & 42.11 & 8.65 & 1.12 & 0.28 & 0.63 & 0.41 & - & - & 32.13 & 0.04 & 8.38 & 4.51 & 1.58 & 0.18 & - \\
\hline & 4 & 36.88 & - & - & - & 0.03 & 0.17 & - & - & 62.02 & 0.90 & - & - & - & - & - \\
\hline \multirow{4}{*}{$\begin{array}{l}\stackrel{艹}{y} \\
\stackrel{ \pm}{ \pm}\end{array}$} & 1 & 73.09 & 24.37 & 1.31 & 0.67 & 0.32 & 0.23 & - & - & - & - & - & - & - & - & - \\
\hline & 2 & 39.67 & 4.05 & 1.21 & 0.26 & 0.10 & 0.13 & 26.38 & 3.54 & 24.47 & 0.19 & - & - & - & - & - \\
\hline & 3 & 48.08 & 1.80 & 2.17 & 0.74 & 0.28 & 0.29 & - & - & 31.55 & 0.07 & 9.00 & 4.19 & 1.18 & 0.13 & 0.52 \\
\hline & 4 & 52.28 & 1.55 & 1.73 & 0.56 & 0.22 & 0.23 & - & - & 31.55 & 0.19 & 6.35 & 2.99 & - & - & 2.34 \\
\hline \multirow{4}{*}{ 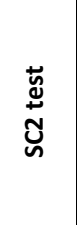 } & 1 & 73.53 & 23.35 & 1.59 & 0.63 & 0.32 & 0.20 & - & - & - & - & - & - & - & - & 0.38 \\
\hline & 2 & 18.03 & 8.20 & 1.72 & 0.32 & 0.12 & 0.25 & 23.20 & 5.39 & 19.03 & 0.21 & - & 0.90 & - & - & 22.63 \\
\hline & 3 & 46.44 & 3.53 & 0.30 & 0.67 & 0.33 & 0.45 & - & - & 40.25 & 0.18 & 4.29 & 2.07 & 0.53 & 0.18 & 0.78 \\
\hline & 4 & 33.39 & 3.38 & - & - & 0.20 & 0.12 & - & - & 61.24 & 0.80 & - & 0.02 & - & - & 0.85 \\
\hline \multirow{2}{*}{$\underset{\amalg}{\breve{y}}$} & 1 & 70.13 & 26.28 & 1.52 & 0.73 & 0.32 & 0.24 & 0.22 & - & - & - & - & 0.38 & - & 0.18 & - \\
\hline & 2 & 19.79 & 12.22 & 2.29 & 0.70 & 0.17 & 0.25 & 23.01 & 1.94 & 19.27 & 0.15 & - & - & - & - & 20.21 \\
\hline
\end{tabular}




\begin{tabular}{|c|c|c|c|c|c|c|c|c|c|c|c|c|c|c|c|c|}
\hline & $\mathbf{3}$ & 63.47 & 0.42 & 0.24 & 0.41 & 0.06 & 0.09 & - & - & 32.76 & 0.12 & 0.95 & 0.49 & - & 0.11 & 0.86 \\
\cline { 2 - 15 } & $\mathbf{4}$ & 46.83 & 0.56 & - & - & 0.06 & 0.12 & - & - & 51.13 & 1.13 & - & - & - & - & 0.17 \\
\hline
\end{tabular}

In the samples exposed to the sulphurous gas, i.e. SC2 and EC2 tests, sulphur is detected mainly in the $\mathrm{Ag}$ and $\mathrm{Cu}$ metallic layer (point 2), whereas only traces of $\mathrm{S}$ are found at the rest of points. Comparing the chemical composition of the metallic layer of these two aged samples with the original one, the percentages of oxygen are slightly lower but the sulphur percentages are over $20 \%$ after the corrosion tests, which indicates the probable main role of the $\mathrm{H}_{2} \mathrm{~S}$ gas in the metal corrosion process. Table 3 shows the relative atomic concentrations of the characteristic oxidants ( $O$ and $S$ ) and the reflectors metals ( $\mathrm{Cu}$ and $\mathrm{Ag}$ ), as well as several atomic ratios between them. The percentages of oxidising species strongly increase after the corrosion tests due to the increment of sulphur, while the metals percentages decrease mainly for the extreme conditions (EC2 test). Thus, the oxidants to metals atomic ratios rise $($ see $(\mathrm{O}+\mathrm{S}) /(\mathrm{Cu}+\mathrm{Ag})$ ratios in Table 3$)$. Since sulphur is a very active oxidant, and regarding $\mathrm{Cu}_{2} \mathrm{~S}$ and $\mathrm{Ag}_{2} \mathrm{~S}$ as the most probable compounds that it can form with copper and silver [7, 26], it can be concluded that all the observed silver and copper atoms may be sulphured, according to the ratios of $\mathrm{S} / \mathrm{Ag}$ and $\mathrm{S} /(\mathrm{Cu}+\mathrm{Ag})$, which are higher than 0.5. Nevertheless, other analysis techniques that are sensitive to metal oxidation states would be necessary to reinforce this conclusion.

Table 3. Relative atomic concentrations (\%) and interesting atomic ratios that show the role of $\mathrm{H}_{2} \mathrm{~S}$ in the corrosion of the metallic layers calculated from EDS microanalyses data.

\begin{tabular}{cccccccc}
\hline Metallic Layer & $\% 0$ & $\% \mathrm{~S}$ & $\% \mathrm{Cu}$ & $\% \mathrm{Ag}$ & $(\mathrm{O}+\mathrm{S}) /(\mathrm{Cu}+\mathrm{Ag})$ & $\mathrm{S} / \mathrm{Ag}$ & $\mathrm{S} /(\mathrm{Cu}+\mathrm{Ag})$ \\
\hline \hline Before test & $22 \pm 7$ & $0.0 \pm 0.0$ & $34.7 \pm 1.4$ & $6.4 \pm 0.5$ & $0.54 \pm 0.20$ & $0.0 \pm 0.0$ & $0.0 \pm 0.0$ \\
After SC2 test & $18 \pm 6$ & $22.6 \pm 0.5$ & $23.2 \pm 1.0$ & $5.4 \pm 0.4$ & $1.4 \pm 0.3$ & $4.2 \pm 0.4$ & $0.79 \pm 0.06$ \\
After EC2 test & $20 \pm 7$ & $20.2 \pm 0.6$ & $23.0 \pm 1.1$ & $1.9 \pm 0.2$ & $1.6 \pm 0.4$ & $10.6 \pm 1.4$ & $0.81 \pm 0.07$ \\
\hline
\end{tabular}

\subsection{Silvered glass reflectors type 2}

Silvered glass reflector type 2 represents the originally undamaged case, featuring its four original protected edges and no scratch. As in the first reflector type studied, the immediate parameter to monitor is the reflectance behaviour throughout the various tests. Fig. 12 illustrates the results of the mean loss in monochromatic specular reflectance at $660 \mathrm{~nm}$ at the nine areas of measurement, i.e. covering the whole reflector surface (a), and the loss in solar-weighted hemispherical reflectance in the central area (b) for this reflector type in the different tests. Neither of the tests gives rise to a significant reduction in these parameters, as can be seen in the steady lines of the graphs. The high homogeneity of these reflectors is represented by the low standard deviations of the different measurement points. 

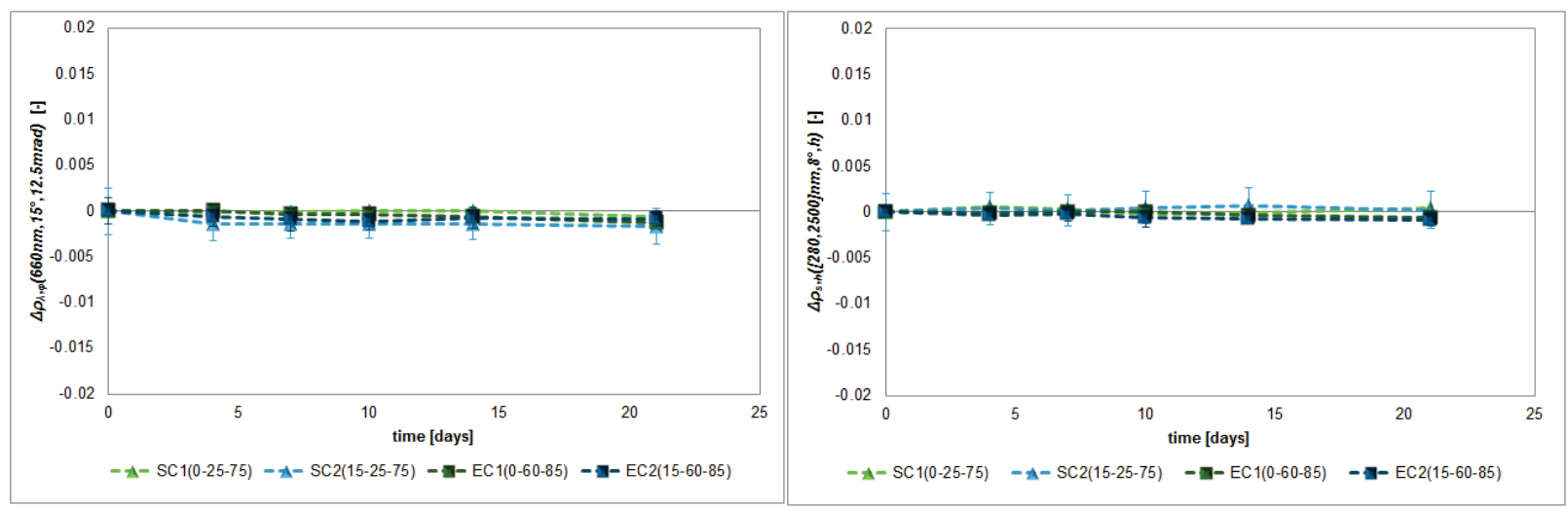

Fig. 12. Evolution along days of the mean change in monochromatic specular reflectance (a) and in solarweighted hemispherical reflectance (b) for silvered glass reflectors type 2 in the different tests (lightgreen triangles for $\mathrm{SC}$, light-blue triangles for $\mathrm{SC2}$, dark-green squares for $\mathrm{EC} 1$ and dark-blue squares for EC2).

Despite the lack of changes obtained in the reflectance monitoring, microscopic inspections do give some noteworthy results. Figs. 13a and $13 \mathrm{~b}$ show two examples of the evolution of the degradation in the reflective layer near the protected edges caused by the EC2 test. Pictures a1 and b1 are taken before the test and pictures $\mathrm{a} 2$ and b2 after it. As can be observed, a substantial number of new corrosion microspots appear after the test. The development of corrosion ranges from a few hundred microns (Fig. 13a2) up to almost $1 \mathrm{~mm}$ penetration from the edge (Fig. 13b2). The degradation pattern near the edges is similar to that of silvered glass reflectors type 1. Apart from corrosion spots, other types of defects characteristic of the presence of the sulphurous gas are corrosion clusters. A corrosion cluster appears as a gathering of microspots not highly concentrated, as if it was an earlier stage in the development of a macrospot. They were found in the reflective layer of silvered glass reflectors types 1 and 2 in the end of SC2 and EC2 tests. Two examples of them are depicted in Figs. 13c and 13d.

Comparisons between the corrosion defects found after the SC2 and EC2 tests for silvered glass reflectors types 1 and 2 are displayed in Table 4. As can be observed, defects are bigger and more frequent for the EC2 test in comparison to the SC2 test. In general, corrosion spots and clusters are more numerous and their maximum size is also higher for silvered glass reflectors type 1 , whereas protected edges are more damaged for silvered glass reflectors type 2 . The high development of corrosion near the protected edges of this type of reflectors could have its origin in the lab-scale process carried out for protecting the edges of such small samples, which differs from the one applied in the real manufacturing line of the entire facets. 

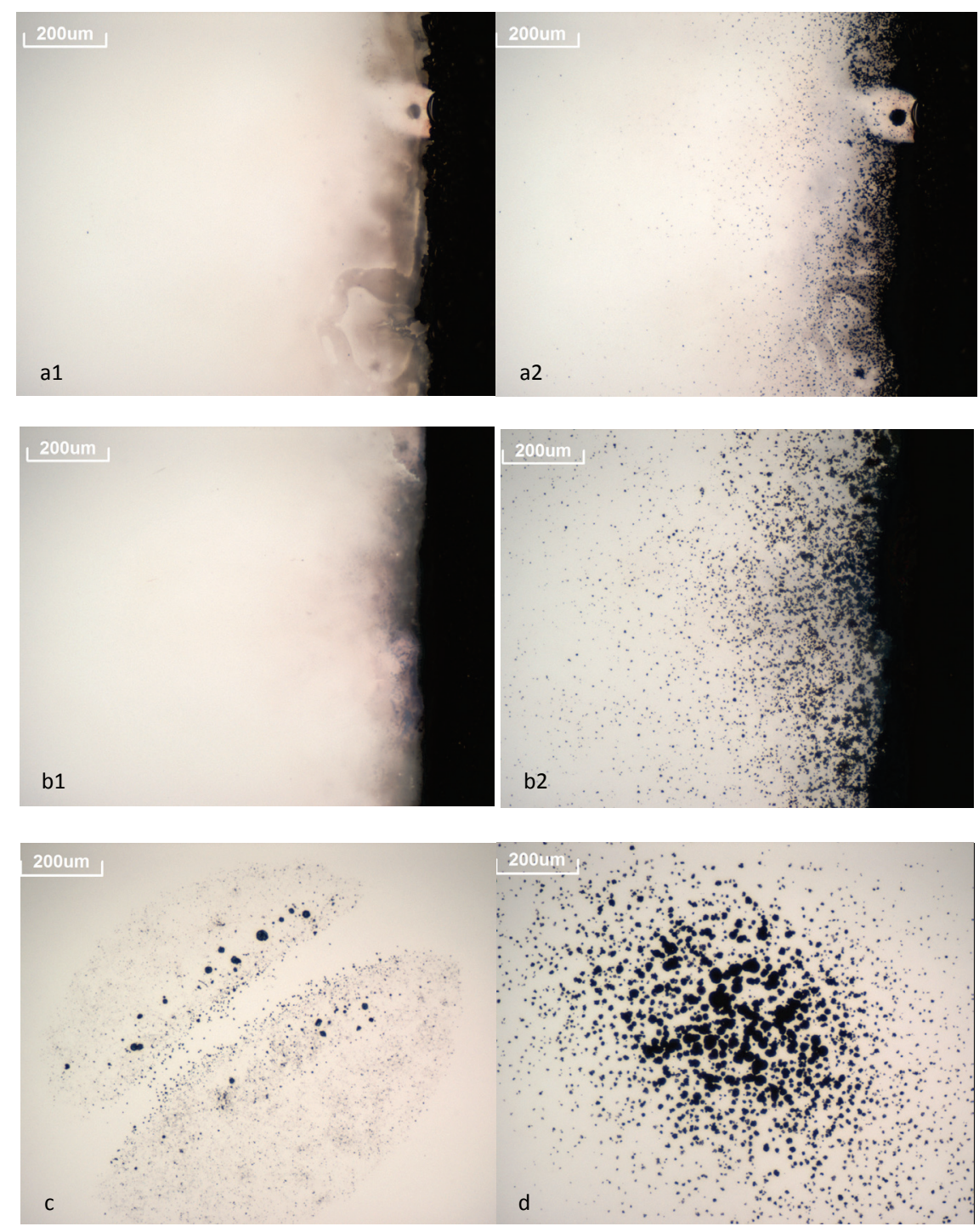

Fig. 13. Different examples of the development of corrosion defects in the reflective layer of silvered glass reflectors type 2 after 21 days of EC2 test: a) low-corroded protected edge before test (a1) and after test (a2); b) high-corroded protected edge before test (b1) and after test (b2); c) corrosion cluster after 21 days of SC2 test; d) corrosion cluster after 21 days of EC2 test.

Table 4. Summary of the corrosion defects found after 21 days of SC2 and EC2 tests for silvered glass reflectors types 1 and 2. Total $N$ : sum of the number of defects visible to the naked eye after 21 days of test in a total reflector surface of $300 \mathrm{~cm}^{2}$; Size: characteristic length of the biggest defect found $(\mu \mathrm{m})$; Max. Pen.: maximum penetration of corrosion near the edge $(\mu \mathrm{m})$. 


\begin{tabular}{|c|c|c|c|c|c|}
\hline \multirow{2}{*}{\multicolumn{2}{|c|}{$\begin{array}{c}\text { Corrosion } \\
\text { defects }\end{array}$}} & \multicolumn{2}{|c|}{ SC2(15-25-75) test } & \multicolumn{2}{|c|}{ EC2(15-60-85) test } \\
\hline & & Silvered glass 1 & Silvered glass 2 & Silvered glass 1 & Silvered glass 2 \\
\hline \multirow{3}{*}{ 范 } & Picture & (8) & * & & P \\
\hline & Total $N$ & 1 & 2 & 19 & 3 \\
\hline & $\begin{array}{l}\text { Size } \\
(\mu \mathrm{m})\end{array}$ & 141 & 112 & 717 & 186 \\
\hline \multirow{3}{*}{ 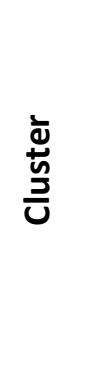 } & Picture & Not found & & & \\
\hline & Total $N$ & 0 & 2 & 55 & 2 \\
\hline & $\begin{array}{l}\text { Size } \\
(\mu \mathrm{m})\end{array}$ & --- & 949 & 702 & 1077 \\
\hline \multirow{2}{*}{ 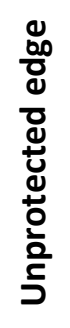 } & Picture & & --- & & --- \\
\hline & $\begin{array}{l}\text { Max. } \\
\text { Pen. } \\
(\mu \mathrm{m})\end{array}$ & 146 & --- & 585 & --- \\
\hline \multirow{2}{*}{ 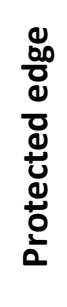 } & Picture & No corrosion & No corrosion & & \\
\hline & $\begin{array}{l}\text { Max. } \\
\text { Pen. } \\
(\mu \mathrm{m})\end{array}$ & No corrosion & No corrosion & 565 & 938 \\
\hline
\end{tabular}

\subsection{Aluminium reflectors}

Similar to silvered glass reflectors type 1, aluminium reflector samples are cut from bigger aluminium sheets and they exhibit four unprotected edges and a scratch at their front side. As in the previous cases, this reflector type is subjected to a number of analyses before and after the corrosion tests. Fig. 14 demonstrates the development of the mean loss in monochromatic specular reflectance at $660 \mathrm{~nm}$ at the eight undamaged areas of measurement (a) and the loss in solar-weighted hemispherical reflectance in the central area (b) for this reflector type in the different corrosion tests already described. No significant decrease in monochromatic specular reflectance is found after the tests, except for a loss of barely -0.002 pp after the EC2 test, which can be considered negligible because it is within the measurement uncertainty of the reflectometer. No significant reduction in solar-weighted 
hemispherical reflectance is either obtained, except for a loss of $-0.002 \mathrm{pp}$ after the SC2 test. The noteworthy standard deviations account for the fact that the surface of aluminium reflectors is quite heterogeneous, which endows them with a not very high specularity compared to silvered glass reflectors. Consequently, it is unlikely to obtain homogeneous results in the measurement of reflectance parameters for this reflector type.

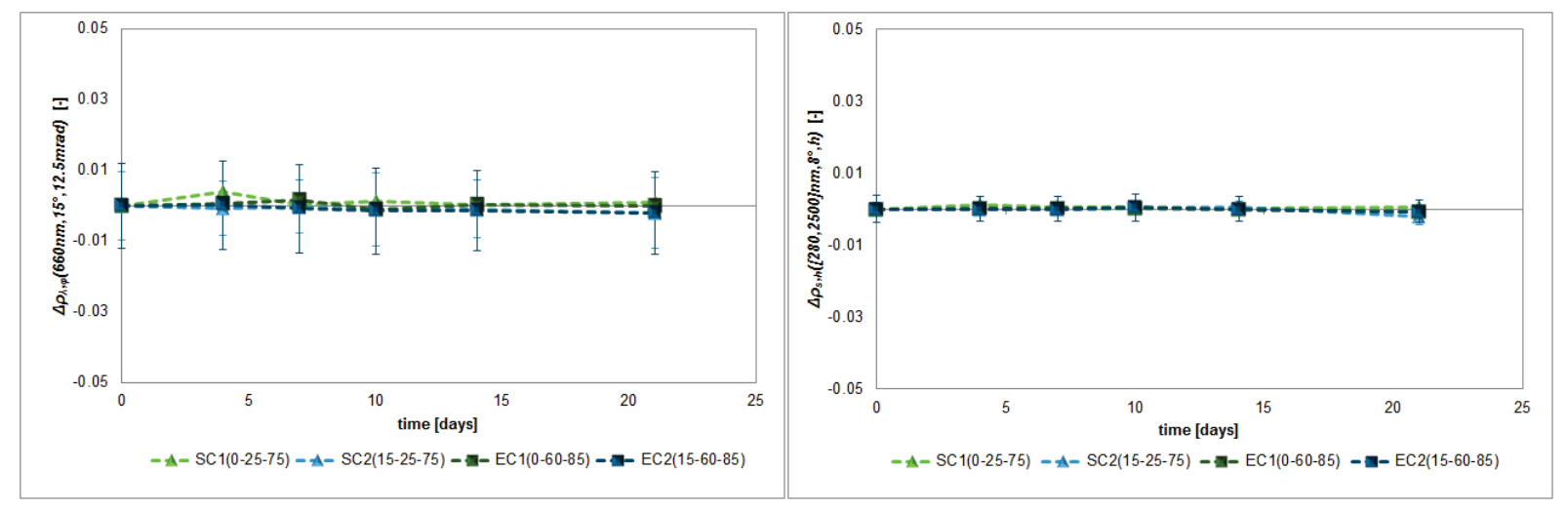

Fig. 14. Evolution along days of the mean change in monochromatic specular reflectance (a) and in solarweighted hemispherical reflectance (b) for aluminium reflectors in the different tests (light-green triangles for SC1, light-blue triangles for SC2, dark-green squares for EC1 and dark-blue squares for EC2).

The loss in monochromatic specular reflectance was also monitored at the scratch. As depicted in Fig. 15, the specular reflectance does not decrease along time in either of the tests. The graph also reveals a high dispersion in the specular reflectance values of the different measurements, as usual for aluminium reflectors.

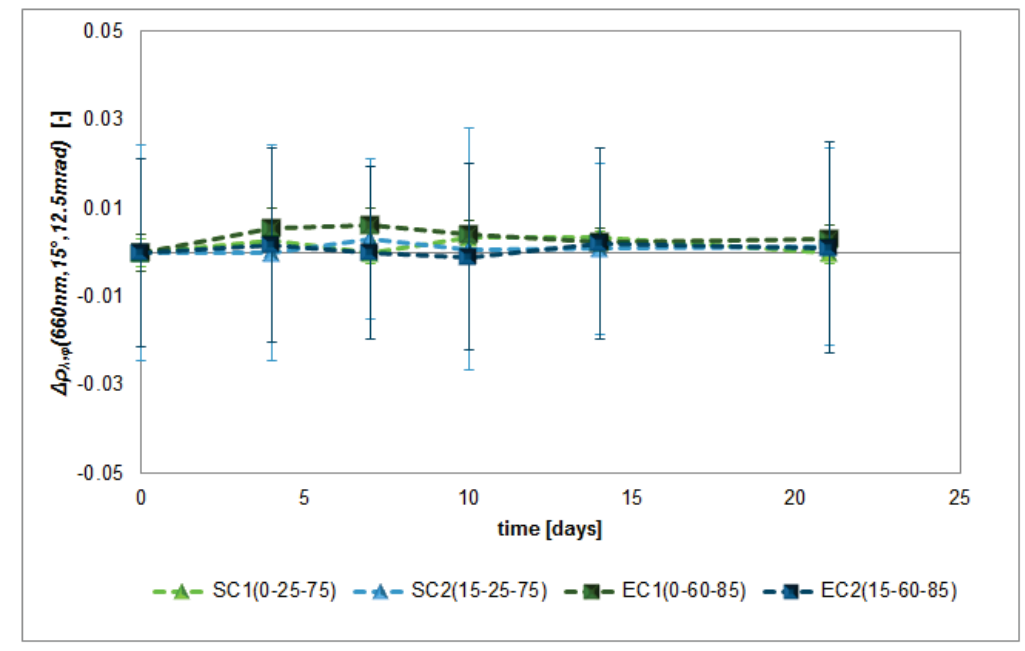

Fig. 15. Evolution along days of the change in monochromatic specular reflectance at the scratch for aluminium reflectors in the different tests (light-green triangles for $\mathrm{SC}$, light-blue triangles for SC2, dark-green squares for EC1 and dark-blue squares for EC2). 
Microscopic inspections were made at the scratch in order to detect any possible corrosion after the tests (Fig. 16). In addition, the development of the scratch width was measured along the different tests (Fig. 17). As can be seen in the microscopic pictures and in the graph, the scratch does not suffer from corrosion along time in either of the tests, and thus there is no increase in its width. Therefore, it can be concluded that the corrosive gas used in the tests $\left(\mathrm{H}_{2} \mathrm{~S}\right)$ hardly affects aluminium reflectors, unlike silvered glass reflectors, as has been already pointed out.

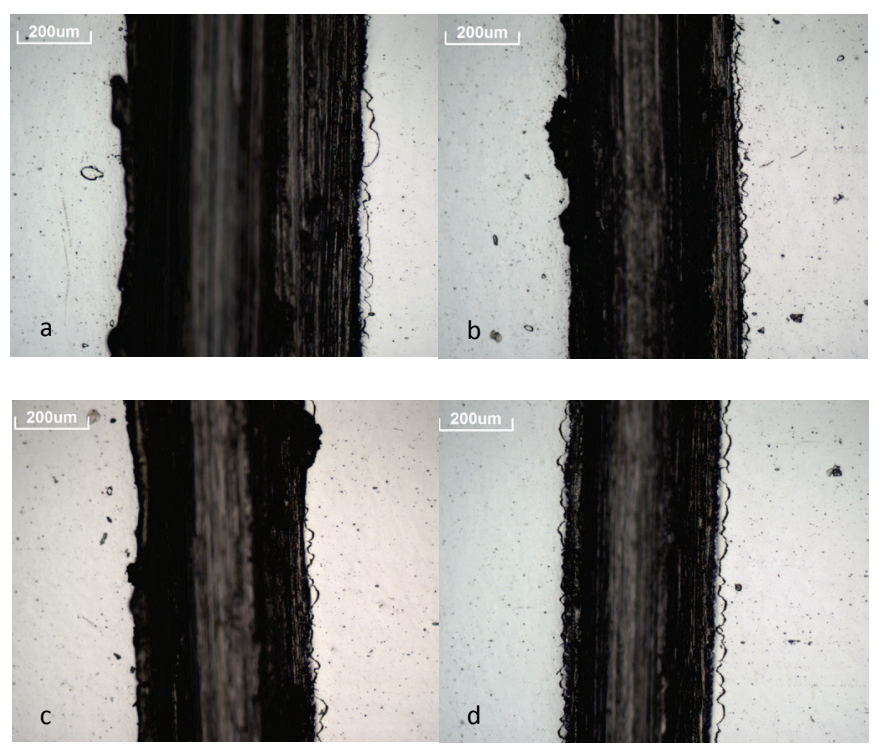

Fig. 16. Microscopic scratch appearance on the front side of aluminium reflectors after 21 days of SC1 (a), EC1 (b), SC2 (c), and EC2 (d) tests.

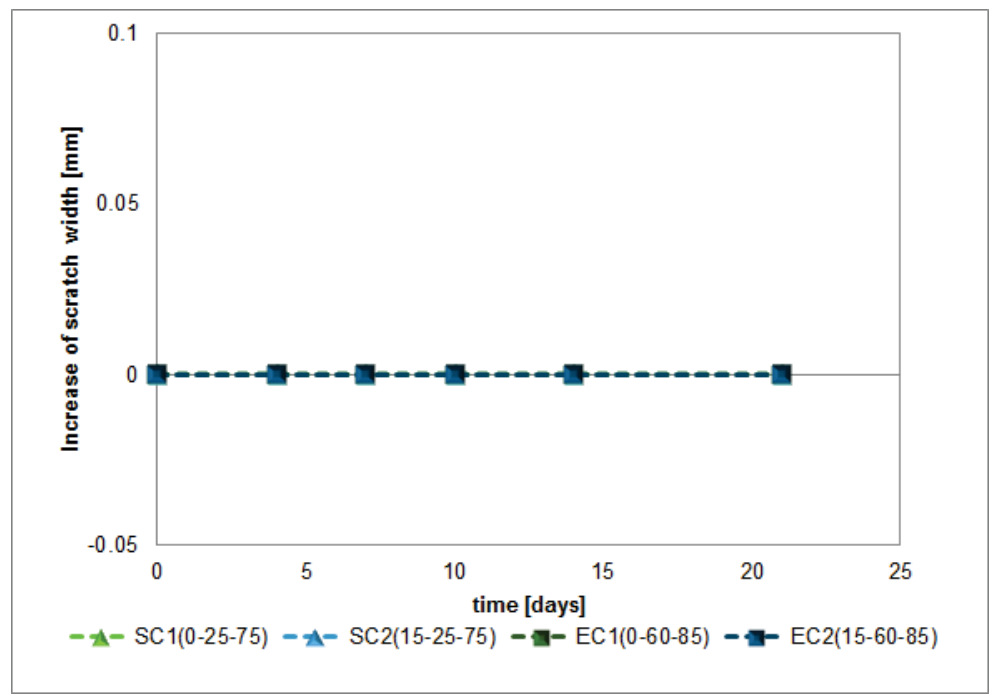

Fig. 17. Evolution along days of the maximum scratch width (in $\mathrm{mm}$ ) for aluminium reflectors in the different tests (light-green triangles for SC1, light-blue triangles for SC2, dark-green squares for EC1 and dark-blue squares for EC2). 
Possible changes in the $2 \mathrm{D}$ profiles of the scratch after the tests were also examined. The initial scratch depth may be variable in the different samples and ranges from 40 to 100 microns, approximately. Fig. 18 exemplifies a typical scratch profile (a) and its microscopic appearance (b) before the tests. The crests that may appear at both sides of the scratch (Fig. 18a) are plastic deformations which are formed on the sample surface after the scratch is done because of the ductile nature of the reflector material.
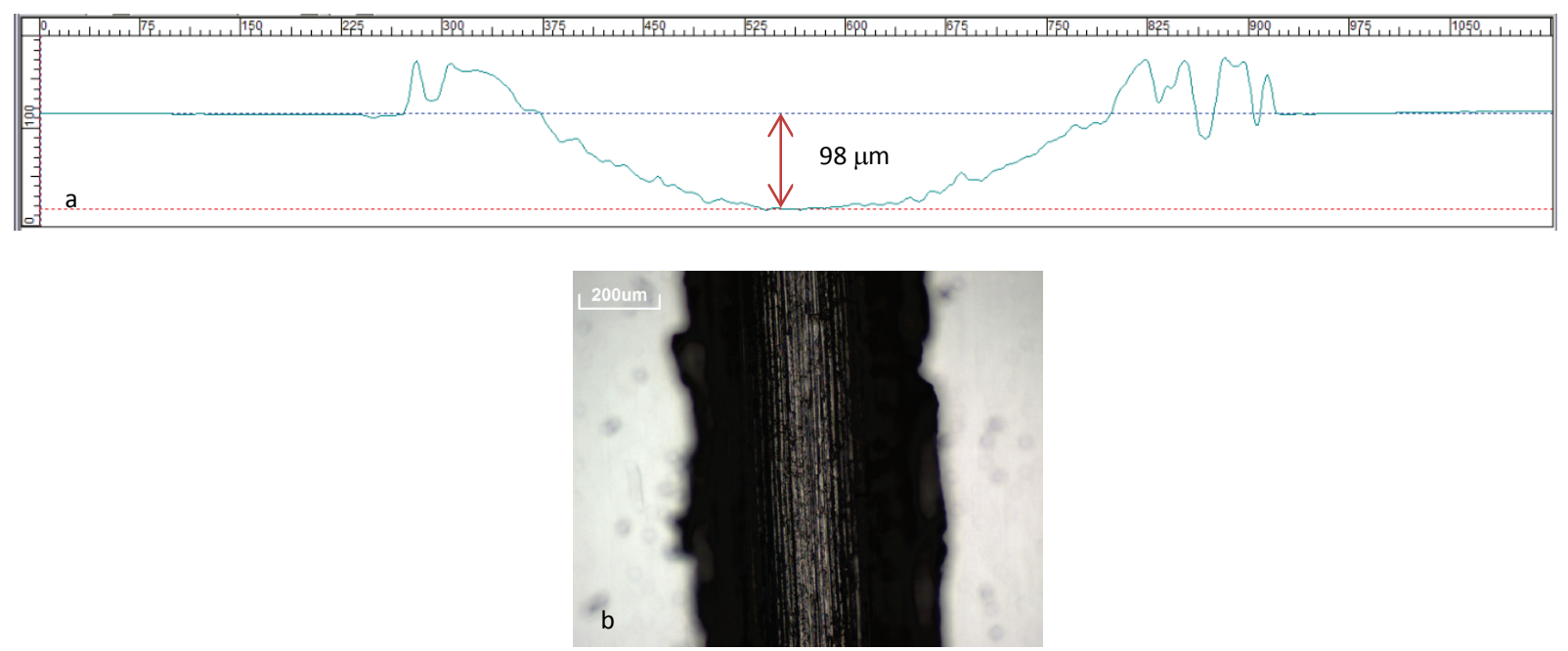

Fig. 18. Typical initial scratch appearance for aluminium reflectors. a) Scratch profile with a depth of $\sim 98 \mu \mathrm{m}$ (contained between the dotted blue and red lines); b) microscopic picture of the scratch focused on its lowest part.

The scratch does not suffer from significant changes in its 2D profile after 21 days of SC1 and EC1 tests (without gas), as can be seen in Figs. 19a and 19b, if compared to Fig. 18a. The appearance of the scratch does not either evolve (Figs. 19a1 and 19b1). Similar results are obtained in the 2D profile of samples after 21 days of SC2 and EC2 tests (with gas), as illustrated in Figs. 19c and 19d. No corrosion products are found in the scratch profiles and no changes are appreciated in either of the samples (Figs. 19c1 and 19d1). The area near the unprotected edges was also inspected but no significant differences are obtained (Fig. 20). These results are in accordance with previous studies [21, 22]. As it was stated in the introduction, aluminium may be more reactive when exposed to chloride-containing environments and to atmospheres with sulphur dioxide, rather than to reduced sulphur compounds, unless they are in solution in the form of sulphates.

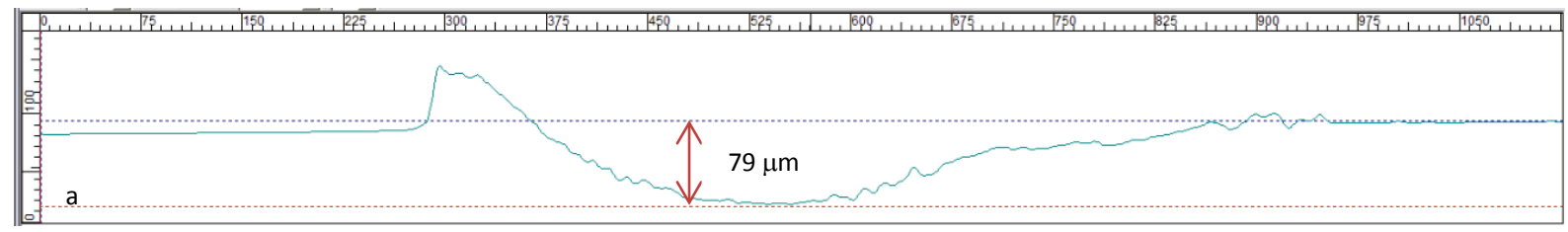



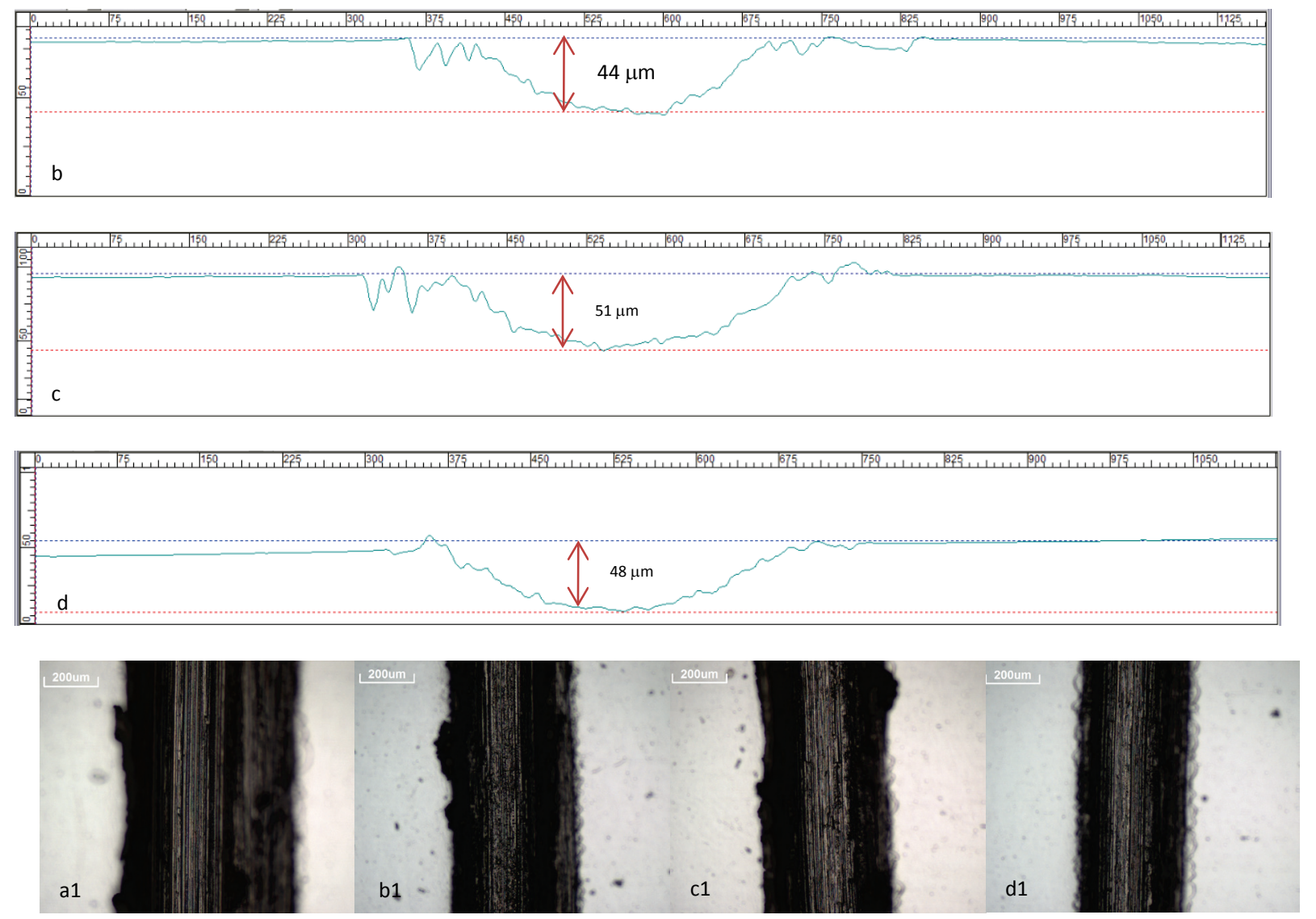

Fig. 19. Scratch profiles for aluminium reflectors after 21 days of SC1 (a), EC1 (b), SC2 (c), and EC2 (d) tests. Below, microscopic pictures of the analysis area focused on the scratch lowest part after SC1 (a1), EC1 (b1), SC2 (c1), and EC2 (d1) tests.

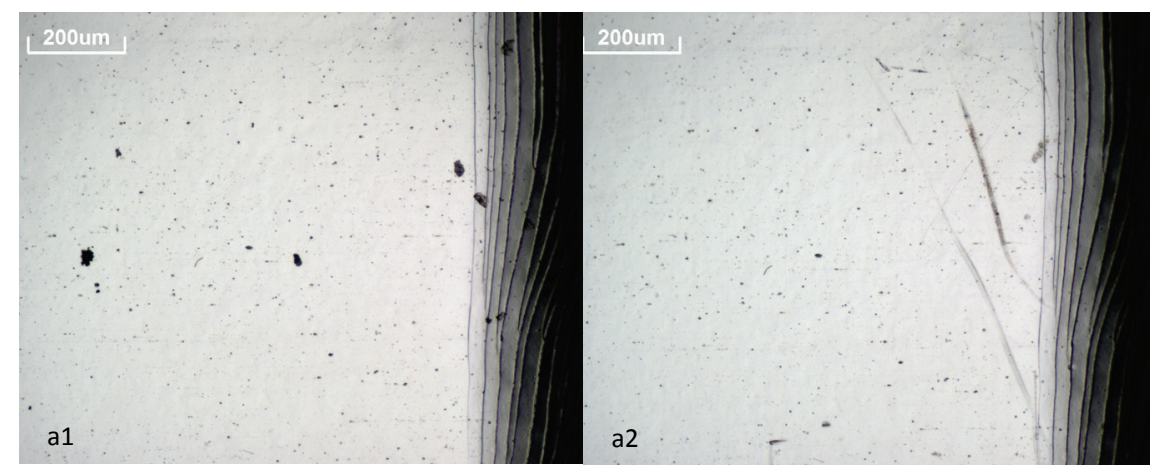

Fig. 20. Unprotected edge of an aluminium reflector before (a1) and after (a2) 21 days of the EC2 test.

\section{Conclusions}

Investigations of the corrosive effects of reduced sulphur atmospheres on reflectors for CSP applications were carried out under accelerated ageing conditions. Three different marketed reflectors of both silvered glass and aluminium types were subjected to corrosion tests, initially based on the international standard IEC 60068-2-43:2003. Two tests included the presence of $\mathrm{H}_{2} \mathrm{~S}$ as the corrosive gas and other 
two reproduced the same conditions without gas. Monochromatic specular reflectance, spectral hemispherical reflectance, optical microscopy, surface profile, SEM and EDS microanalyses were used to study the corrosion of the reflector materials. Special attention was paid on the scratch, i.e. an initial damage applied to the reflector in which the metal layers are directly exposed to the corrosive atmosphere.

Although traditional reflectance measurement methods are not able to detect almost any reflectance loss after the ageing of samples (except in the scratch area), optical microscopic inspections show corrosion defects in the reflective layer of silvered glass reflectors. The pattern of degradation caused by the $\mathrm{H}_{2} \mathrm{~S}$ in the silvered glass reflectors mainly consists in corrosion spots. Their initial stage is normally in the form of microspots, which are black spots smaller than $200 \mu \mathrm{m}$ and thus not visible to the naked eye. They can either grow near the edge (protected or unprotected) or anywhere else in the reflective layer. A more developed stage of corrosion spots is macrospots, which are concentrations of microspots that can reach characteristic lengths larger than $700 \mu \mathrm{m}$. Another configuration of microspots occurs when they gather together forming corrosion clusters. They are not as intense as the macrospots and could be considered as a previous stage in their evolution, although their characteristic length may attain $1 \mathrm{~mm}$. In addition, EDS microanalyses reveal the effective reaction between the sulphurous gas and the metallic parts of the silvered glass reflectors, especially with their reflective layer of silver and copper. Comparing the two types of silvered glass reflectors, the development of microspots from the edge is higher for the reflectors with four protected edges (type 2), taking into account that their manufacturing process has been adapted to produce very small facets of $(10 \times 10) \mathrm{cm}^{2}$. However, fewer corrosion defects appear in the rest of the reflective layer of type 2 reflectors, in contrast to type 1 reflectors. Unlike silvered glass reflectors, aluminium ones do not corrode in the presence of the sulphurous gas. This is in accordance with previous studies, which report that $\mathrm{H}_{2} \mathrm{~S}$ hardly affects aluminium.

It can be concluded that sulphurous atmospheres, like the one studied in this article, do harm the performance of certain CSP reflectors. Appropriate assessment techniques that allow the detection of corrosion in their reflective layer are of vital importance. Therefore, the study of the corrosion of solar reflector materials by industrial gases is an interesting research area, which should be also explored in other scenarios such as humid corrosion and gases combinations to decide which accelerated corrosion tests are more appropriate for service life prediction of solar reflector materials.

\section{Acknowledgements}

This work has been developed under the framework of the Spanish Project DETECSOL (grant $\mathrm{n}^{\circ}$ ENE2014-56079-R) supported by the Programa Estatal de Investigación, Desarrollo e Innovación orientada a los Retos de la Sociedad (National Program of Research, Development and Innovation oriented to Society's Challenges) of the Ministerio de Economía y Competitividad (Spanish Ministry of Economy and Competitiveness). Additionally, the research leading to this work has also received funding from the EU Horizon 2020 - H2020-LCE-2016-2017 under grant agreement nº 731287 (Integrating National Research Agendas on Solar Heat for Industrial Processes, INSHIP). 


\section{References}

[1] A. Jäger-Waldau, Photovoltaics and renewable energies in Europe, Renew. Sustain. Energy Rev. 11 (2007) 1414-1437. doi:10.1016/j.rser.2005.11.001.

[2] D. Barlev, R. Vidu, P. Stroeve, Innovation in concentrated solar power, Sol. Energy Mater. Sol. Cells. 95 (2011) 2703-2725. doi:10.1016/j.solmat.2011.05.020.

[3] Renewables 2016 Global Status Report, Technical Report, ISBN 978-3-9818107-0-7, Renewable Energy Policy Network for 21st century, REN21 Secretariat, Paris, France, 2016.

[4] European Solar Thermal Electricity Association (ESTELA): "The value of Solar Thermal Electricity". http://www.estelasolar.org/our-activities/communication-and-media/publications/, 2016 (accessed 07.06.17).

[5] S. Meyen, A. Fernández-García, C. Kennedy, E. Lüpfert, Standardization of solar mirror reflectance measurements--round robin test, 16th SolarPACES Conf. (2010). http://www.nrel.gov/docs/fy11osti/49189.pdf.

[6] C. Hillman, J. Arnold, S. Binfield, J. Seppi, Silver and Sulfur : Case Studies, Physics, and Possible Solutions, STMA Int. Conf. (2007).

[7] D.W. Rice, Atmospheric corrosion of copper and silver, J. Electrochem. Soc. 128 (1981) 275-284. doi:10.1017/CBO9781107415324.004.

[8] E. Eijo-Río, A. Petit-Boix, G. Villalba, M.E. Suárez-Ojeda, D. Marin, M.J. Amores, X. Aldea, J. Rieradevall, X. Gabarrell, Municipal sewer networks as sources of nitrous oxide, methane and hydrogen sulphide emissions: A review and case studies, J. Environ. Chem. Eng. 3 (2015) 20842094. doi:10.1016/j.jece.2015.07.006.

[9] D.W. Rice, R.J. Cappell, W. Kinsolving, J.J. Laskowski, Indoor corrosion of metals, J. Electrochem. Soc. 127 (1980) 891-901. doi:10.1149/1.2129780.

[10] B.H. Chudnovsky, Degradation of power contacts in industrial atmosphere: silver corrosion and whiskers, Proc. Forty-Eighth IEEE Holm Conf. Electr. Contacts. (2002) 1-22. doi:10.1109/HOLM.2002.1040834.

[11] E. Johansson, C. Leygraf, Corrosion measurements of silver and copper in indoor atmospheres using different evaluation techniques, Br. Corros. J. 34 (1999) 27-33.

doi:10.1179/bcj.1999.34.1.27.

[12] S. Syed, Atmospheric corrosion of materials, Emirates J. Eng. Res. 11 (2006) 1-24. http://eclsun.uaeu.ac.ae/ejer/issues/V11/pdf_iss1_11/p1_ATMOSPHERIC_CORROSION_OF_MAT ERIALS.pdf.

[13] A. Fernández-García, E. Zarza, L. Valenzuela, M. Pérez, Parabolic-trough solar collectors and their applications, Renew. Sust. Energy Rev. 14 (2010) 1695-1721.

[14] A. García-Segura, A. Fernández-García, M.J. Ariza, F. Sutter, L. Valenzuela, Durability studies of solar reflectors: A review, Renew. Sustain. Energy Rev. 62 (2016) 453-467. 


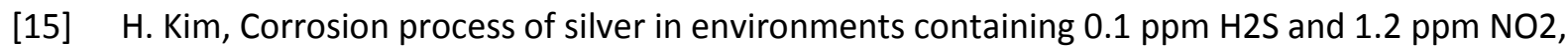
Mater. Corros. 54 (2003) 243-250. doi:10.1002/maco.200390053.

[16] L. Volpe, P.J. Peterson, The atmospheric sulfidation of silver in a tubular corrosion reactor, Corros. Sci. 29 (1989). doi:10.1016/0010-938X(89)90065-6.

[17] W. Abbott, Effects of Industrial Air Pollutants on Electrical Contact Materials, IEEE Trans. Parts, Hybrids, Packag. PHP-10 (1974) 24-27. doi:10.1109/TPHP.1974.1134830.

[18] H.E. Bennett, R.L. Peck, D.K. Burge, J.M. Bennett, Formation and growth of tarnish on evaporated silver films, J. Appl. Phys. 40 (1969) 3351-3360. doi:10.1063/1.1658187.

[19] H. Lin, G.S. Frankel, W.H. Abbott, Analysis of Ag corrosion products, J. Electrochem. Soc. 160 (2013) C345-C355. doi:10.1149/2.055308jes.

[20] Y. Fukuda, T. Fukushima, a. Sulaiman, I. Musalam, L. C.Yap, L. Chotimongkol, S. Judabong, a. Potjanart, O. Keowkangwal, K. Yoshihara, M. Tosa, Indoor Corrosion of Copper and Silver Exposed in Japan and ASEAN 1 Countries, J. Electrochem. Soc. 138 (1991) 1238-1243. doi:10.1149/1.2085766.

[21] T.E. Graedel, Corrosion mechanisms for aluminum exposed to the atmosphere, J. Electrochem. Soc. 136 (1989) 204C-212C. doi:10.1149/1.2096869.

[22] M. Morcillo, B. Chico, D. De La Fuente, J. Simancas, Looking back on contributions in the field of atmospheric corrosion offered by the MICAT ibero-american testing network, Int. J. Corros. 2012 (2012). doi:10.1155/2012/824365.

[23] IEC 60721-3-3, Classification of environmental conditions. Part 3-3: Classification of groups of environmental parameters and their severities. Stationary use at weatherprotected locations, Publication Date: Oct 1, 2002.

[24] C.J. Yang, C.H. Liang, X. Liu, Tarnishing of silver in environments with sulphur contamination, AntiCorrosion Methods Mater. 54 (2007) 21-26. doi:10.1108/00035590710717357.

[25] C.O. Muller, Multiple Contaminant Gas Effects on Electronic Equipment Corrosion, (1991) 146151.

[26] T.E. Graedel, J.P. Franey, G.J. Gualtieri, G.W. Kammlott, D.L. Malm, On the mechanism of silver and copper sulfidation by atmospheric H2S and OCS, Corros. Sci. 25 (1985) 1163-1180. doi:10.1016/0010-938X(85)90060-5.

[27] T.E. Graedel, Corrosion mechanisms for silver exposed to the atmosphere, J. Electrochem. Soc. 139 (1992) 1963-1970. doi:10.1017/CBO9781107415324.004.

[28] H. Gil, C.P. Buitrago, A. Echavarría, Characterization of atmospheric corrosion products formed on silver in tropical-mountain environments, J. Solid State Electrochem. 19 (2015) 1817-1825. doi:10.1007/s10008-015-2821-z.

[29] J.P. Franey, G.W. Kammlott, T.E. Graedel, The corrosion of silver by atmospheric sulfurous gases, Corros. Sci. 25 (1985) 133-143. doi:10.1016/0010-938X(85)90104-0. 
[30] C.E. Sanders, D. Verreault, G.S. Frankel, H.C. Allen, The Role of Sulfur in the Atmospheric Corrosion of Silver, J. Electrochem. Soc. 162 (2015) C630-C637. doi:10.1149/2.0051512jes.

[31] IEC 60068-2-43:2003, Environmental testing - Part 2-43: Tests - Test Kd: Hydrogen sulphide test for contacts and connections, 2003.

[32] Scratching Tool acc. to van Laar, Model 426. ERICHSEN GmbH \& Co. KG, https://www.erichsen.de/corrosion-testing/specimen-preparation/scratching-tool-acc-to-vanlaar-model-426/technical-description-model-426-pdf/download (accessed 07.06.17).

[33] F. Wiesinger, F. Sutter, A. Fernández-García, J. Reinhold, R. Pitz-Paal, Sand erosion on solar reflectors: accelerated simulation and comparison with field data, Sol. Energy Mater. Sol. Cells. 145 (2016) 303-313. Doi: 10.1016/j.solmat.2015.10.036.

[34] Devices and Services. Portable Specular Reflectometer Model 15R-USB. Operation and Maintenance Manual. Dallas: Devices and Services (D\&S), 2009.

[35] Perkin Elmer. High Performance Lambda Spectrophotometers. Hardware Guide. United Kingdom: Perkin Elmer, 2007.

[36] ISO 9050. Glass in building, Determination of light transmittance, solar direct transmittance, total solar energy transmittance, ultraviolet transmittance and related glazing factors. Geneva: International Organization for Standardization (ISO), 2003.

[37] ASTM standard G173-03. Terrestrial Reference Spectra for Photovoltaic Performance Evaluation. West Conshohocken: American Society for Testing and Materials (ASTM), 2003. 